\title{
THE ROLE OF CONTEXT IN WORK TEAM DIVERSITY RESEARCH: A META-ANALYTIC REVIEW
}

\author{
APARNA JOSHI \\ HYUNTAK ROH \\ University of Illinois at Urbana-Champaign
}

\begin{abstract}
Integrating macro and micro theoretical perspectives, we conducted a meta-analysis examining the role of contextual factors in team diversity research. Using data from 8,757 teams in 39 studies conducted in organizational settings, we examined whether contextual factors at multiple levels, including industry, occupation, and team, influenced the performance outcomes of relations-oriented and task-oriented diversity. The direct effects were very small yet significant, and after we accounted for industry, occupation, and team-level contextual moderators, they doubled or tripled in size. Further, occupation- and industry-level moderators explained significant variance in effect sizes across studies.
\end{abstract}

Research in the area of work team diversity has grown exponentially in the last four decades. However, several comprehensive reviews have noted that the findings in this area do not provide a clear consensus regarding the performance effects of work team diversity (Harrison \& Klein, 2007; Jackson, Joshi, \& Erhardt, 2003; Milliken \& Martins, 1996; Van Knippenberg \& Schippers, 2007; Williams \& O’Reilly, 1998). In some studies, researchers have reported that team diversity is positively associated with performance (e.g., Ely, 2004; Van der Vegt, Van de Vliert, \& Huang, 2005). In another set of studies, team diversity has been found to negatively predict performance (e.g., Jehn, Northcraft, \& Neale, 1999; Leonard, Levine, \& Joshi, 2004). A majority of these studies, however, have reported a nonsignificant, direct relationship between team diversity and performance. Furthermore, even within studies, the effects of gender, race, age, and tenure diversity on team performance have varied (e.g., Kirkman, Tesluk, \& Rosen, 2004; Kochan et al., 2003).

Current theoretical perspectives framing diversity research, such as social identity theory, social categorization theory, and the attraction-selectionattrition framework, appear to be insufficient for resolving these mixed findings. In general, current

A version of this paper was presented at the 2008 Annual Meeting of the Academy of Management and won the Dorothy Harlow Distinguished Paper Award. We are indebted to Joseph Martocchio for advice and feedback on drafts of this work. We are also extremely grateful to Jason Colquitt and three anonymous reviewers for invaluable feedback throughout the review process. We thank Niti Pandey and Erik Young for research assistance. applications of these theoretical perspectives have offered broad generalizations for why differences within work groups may manifest in specific attitudinal outcomes, such as conflict or cohesion, or in behavioral outcomes, such as turnover or absenteeism (see Jackson et al., 2003). In addition to asking why diversity manifests in specific outcomes, a careful examination of situational settings would also ask when, where, and how diversity dynamics unfold in workplaces; these contextual considerations, not often captured (see Johns, 2006), are pertinent for reconciling the mixed findings from past research. Researchers have attempted to reconcile these findings within prevalent theoretical traditions by considering the influence of organization-level and team-level factors on diversity outcomes (e.g., Kirkman et al., 2004; Kochan et al., 2003). However, these explanations are often offered post hoc; contextual factors have less often been incorporated in hypothesis development or in study design. We propose that a unified and comprehensive contextual framework for diversity research has the potential to resolve these inconsistent findings and can contribute to further theoretical and empirical developments in the field.

This article highlights contextual issues in team diversity research. Our study takes a substantively different approach from past meta-analytic reviews on this topic (Bowers, Pharmer, \& Salas, 2000; Horwitz \& Horwitz, 2007; Webber \& Donahue, 2001). Rather than test whether diversity attributes have a positive or a negative effect on team performance, we accounted for aspects of context at multiple levels and examined whether these contextual factors shaped the team diversity-performance relationship. In proposing and testing the contextual 
framework presented in this article, we attempt to make several contributions to work team diversity research. First, we develop and test a theoretically driven framework for work team diversity context across multiple levels of analysis. Several researchers have acknowledged that contextual considerations are critical in diversity research (e.g., Jackson et al., 2003; Martins, Milliken, Wiesenfeld, \& Salgado, 2003). However, a theoretically driven multilevel framework explicating contextual determinants of work team diversity outcomes has not been forthcoming. Our study addresses this gap. Some scholars have also drawn attention to structural and institutional factors that give meaning to demographic differences in organizations (DiTomaso, Post, \& Parks-Yancy, 2007; Ragins \& Sundstorm, 1990). Yet the prevalent theoretical perspectives we referred to in our introduction do not account for these institutional and structural factors. Therefore, a second contribution we attempt is an integration of work team diversity research with macro theoretical perspectives that account for these factors and have received relatively scant attention in the past. Furthermore, team task characteristics can also shape the salience of diversity attributes within teams (Van Knippenberg \& Schippers, 2007); we also consider whether these characteristics are a relevant team-level context influencing the diversity-performance link. Third, we integrate 15 years of field research on the performance outcomes of work team diversity. Our review distinguishes between the effects of task-oriented (e.g., function, education, and tenure) and relations-oriented (e.g., gender, race/ethnicity, and age) aspects of diversity in relation to performance. Finally, this study answers a call in the broader domain of management research for a more context based understanding of workplace phenomena (Bamberger, 2008; Johns, 2006; Rousseau \& Fried, 2001). Context theorizing in management research can enhance its "market orientation," which not only makes study findings more accessible to managers but is also important for future theory building (Bamberger, 2008; Dubin, 1976).

In the following section, we discuss in detail how we conceptualize diversity context and outline various aspects of this context. Next, we develop hypotheses that delineate the moderating effects of these contextual factors on team diversity in relation to team performance. Finally, we present the findings from a meta-analytic review and consider the implications of these contextual considerations for future theoretical and empirical developments in diversity research.

\section{KEY CONCEPTS AND THEORETICAL BACKGROUND}

We define diversity as an aggregate team-level construct that represents differences among members of an interdependent work group with respect to a specific personal attribute (Jackson et al., 2003). In line with past research, we distinguish between task-oriented and relations-oriented aspects of diversity (Jackson, May, \& Whitney, 1995). Relations-oriented diversity attributes such as gender, race/ethnicity, and age are cognitively accessible, pervasive, and immutable and are associated with social categorization processes (Fiske, 1998; Van Knippenberg, De Dreu, \& Homan, 2004). These social categorization-based processes, which manifest in intergroup bias and negative attitudes toward dissimilar others in a group may have negative performance consequences. In contrast, taskoriented diversity attributes, such as education, function, and tenure, are associated with skill-based and informational differences among work group members (Jackson et al., 1995). These aspects of diversity are assumed to constitute a team's cognitive resource base and are associated with elaborationbased processes, defined as the exchange of information and perspectives among group members, individual-level information processing, gaining feedback, and integrating information and perspectives. These elaboration-based processes explain the positive performance outcomes of work group diversity (see Van Knippenberg et al., 2004). In the subsequent sections, we discuss how various aspects of diversity context can influence the categorization-based processes associated with relations-oriented diversity and the elaborationbased processes associated with task-oriented diversity, and implications for team performance. Although more sophisticated conceptualizations of team diversity have been developed (e.g., Harrison \& Klein, 2007; Lau \& Murnighan, 1998), we draw on a more simplified yet established typology of diversity attributes to develop our key propositions regarding the role of contextual factors in diversity research. ${ }^{1}$

Team performance is defined as the extent to

\footnotetext{
${ }^{1}$ Some researchers have also conceptualized team diversity by differentiating between surface- and deeplevel diversity (e.g., Harrison, Price, \& Bell, 1998). Other researchers have proposed an approach based on "faultlines" (e.g., Lau \& Murnighan, 1998). Recently, Harrison and Klein (2007) posed "separation," "variety," and "disparity" as diversity dimensions to consider. We discuss these alternative approaches later, in the Discussion section.
} 
which a team accomplishes its goal or mission (Devine \& Phillips, 2001). We focus on performance as an outcome of diversity because this outcome has received the most research attention and represents an area in which the mixed findings have been the most prevalent (Jackson et al., 2003). Results pertaining to performance outcomes of diversity may need the most integration, and understanding the contextual factors shaping performance outcomes may have the most value for resolving past findings.

Context has been defined as the situational setting in which workplace phenomena occur (Cappelli \& Sherer, 1991). In recent theoretical advancements, it has been recognized that various aspects of context may serve as "situational opportunities for and countervailing constraints against organizational behavior [and] be represented as a tension system or force field comprising such opportunities and constraints" (Johns, 2006: 387). Drawing on this perspective, we propose that context can set specific constraints and opportunities that either enhance or minimize the direct effects of work team diversity on performance. Opening the discourse on team diversity to contextual influences is challenging because it requires one to specify team, organizational, and extraorganizational factors that may comprise a "tension system" shaping diversity effects. Therefore, we undertook an extensive review of team diversity research conducted in organizational settings from 1992 through 2008 to identify aspects of diversity context that past research has explicitly acknowledged as either moderator or as control variables. Table 1 represents the findings of this review.

Our review indicated that approximately 60 percent of the direct effects reported in past research were nonsignificant for various diversity attributes. Among the remainder, 20 percent of the effects reported were significantly positive, and 20 percent were significantly negative. Researchers have considered contextual variables primarily at the team level to explicate these mixed effects of team diversity on performance. Among the studies we reviewed, over 70 percent accounted for team-level contextual factors such as task interdependence, complexity, climate, and other team-level perceptual variables (e.g., Jehn et al., 1999; Pelled, Eisenhardt, \& Xin, 1999; Schippers, Den Hartog, Koopman, \& Wienk, 2003; Van der Vegt \& Bunderson, 2005). Approximately 20 percent of the studies represented in Table 1 examined contextual moderators at the organizational level, including organizational demography, diversity training participation, and organizational culture (e.g., Ely, 2004; Jackson \& Joshi, 2004; Jehn \& Bezrukova, 2004). Less than 10 percent of the studies reviewed examined extraorganizational factors.
Among the studies that did incorporate these variables, the focus was on national culture, customer base demography, market competition, and rate of technological change (e.g., Ancona \& Caldwell, 1992; Lovelace, Shapiro, \& Weingart, 2001; Leonard et al., 2004; Reagans \& Zuckerman, 2001; Van der Vegt et al., 2005). On the basis of this review, we aimed to take stock of contextual effects that are conceptually distinct and have been considered in past research and also to incorporate additional contextual variables that have received less attention in the past.

Theoretical and practical considerations governed our efforts to identify key contextual factors. Sociopsychological theoretical perspectives suggest that the demography of the job or occupation in which diverse work groups are embedded can shape categorization-based processes in these groups (DiTomaso, Post, \& Parks-Yancy, 2007; Larkey, 1996; Reskin, McBrier, \& Kmec, 1999). ${ }^{2}$ Unlike in a balanced setting, in an occupational context dominated by a single demographic group, negative stereotypes about underrepresented groups can influence categorization-based outcomes within work groups (Hilton \& Von Hippel, 1996; Larkey, 1996). We extend these perspectives to focus on occupational demography as a contextual factor that can enhance or minimize the influence of team diversity on performance outcomes.

We also consider industry as an embedding context for diversity-based outcomes. Strategic management research suggests that interindustry variation in levels of technological change, regulatory pressure, customer demands, and market competition are greater than intraindustry variations (Bourgeois, 1985; Porter, 1980). Furthermore, these industry-level contingencies can serve as situational enhancers or minimizers of diversity effects on performance (Hambrick, Cho, \& Chen, 1996; Richard, Murthi, \& Ismail, 2007). Within the strategic management domain, considerable research on top management teams and research on the firm diversity-performance link has incorporated industrylevel context (e.g., service versus manufacturing) as a key moderator (e.g., Haleblian \& Finkelstein, 1993; Hambrick et al., 1996; Keck, 1997; Richard et al., 2007). We extend these perspectives to consider industry setting as a relevant aspect of a team's

\footnotetext{
${ }^{2}$ We acknowledge that the proximal work context represented by organization-level demography, culture, and climate has received some attention in past research and that these are also important contextual variables to consider. However, of the studies included in this review, only three provided information regarding organization-level demography, culture, or climate, and therefore these variables could not be included in the meta-analysis.
} 


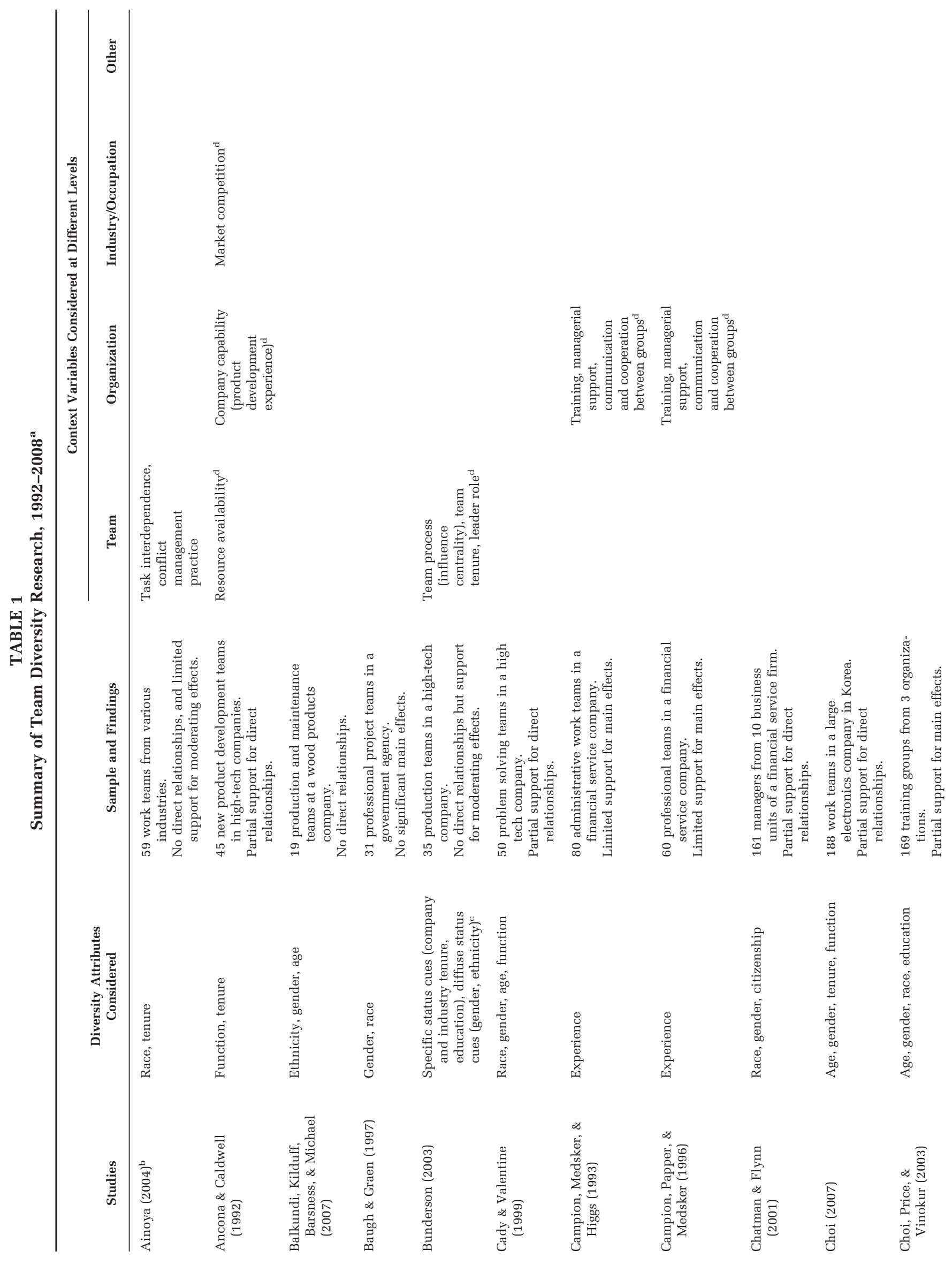



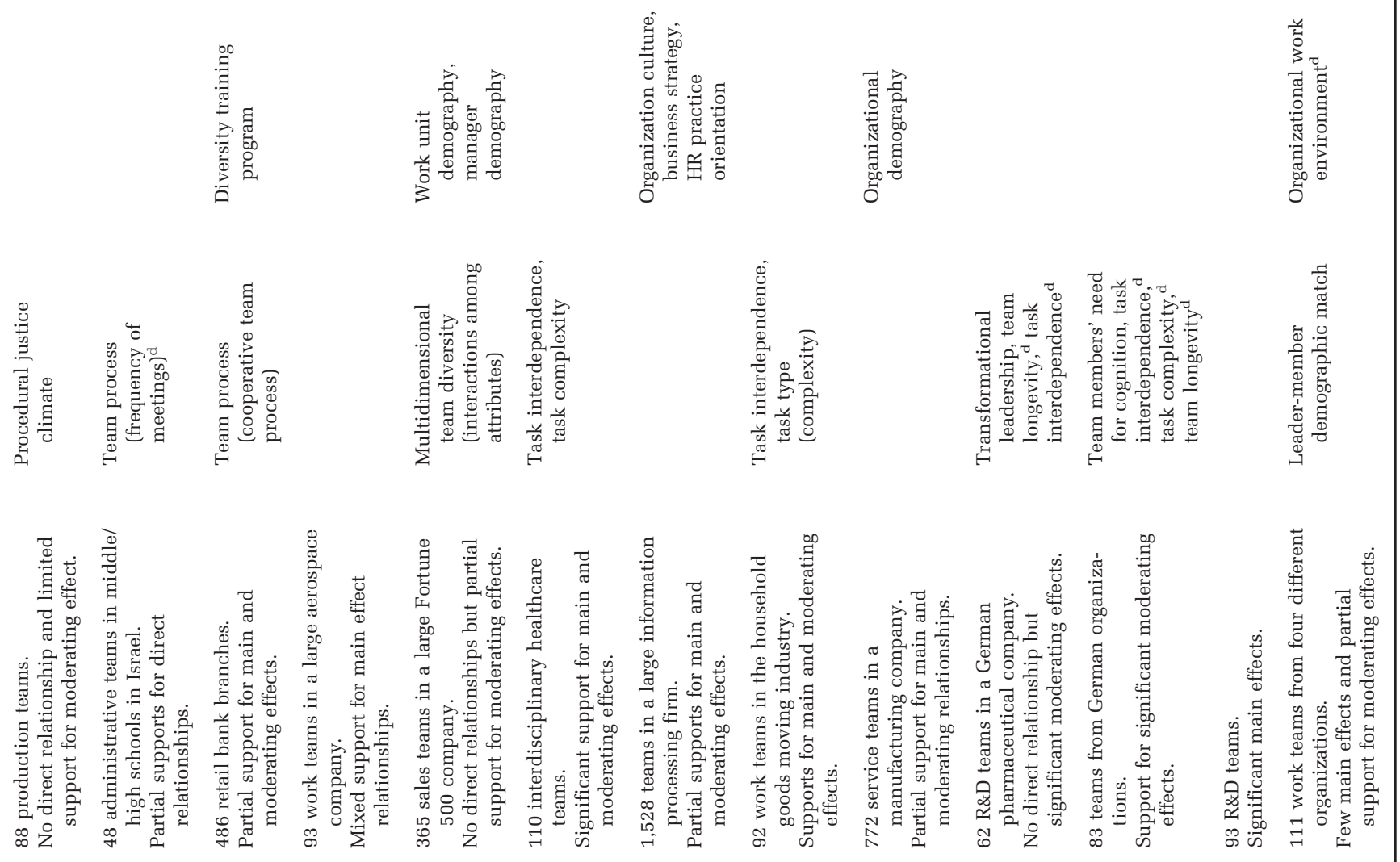

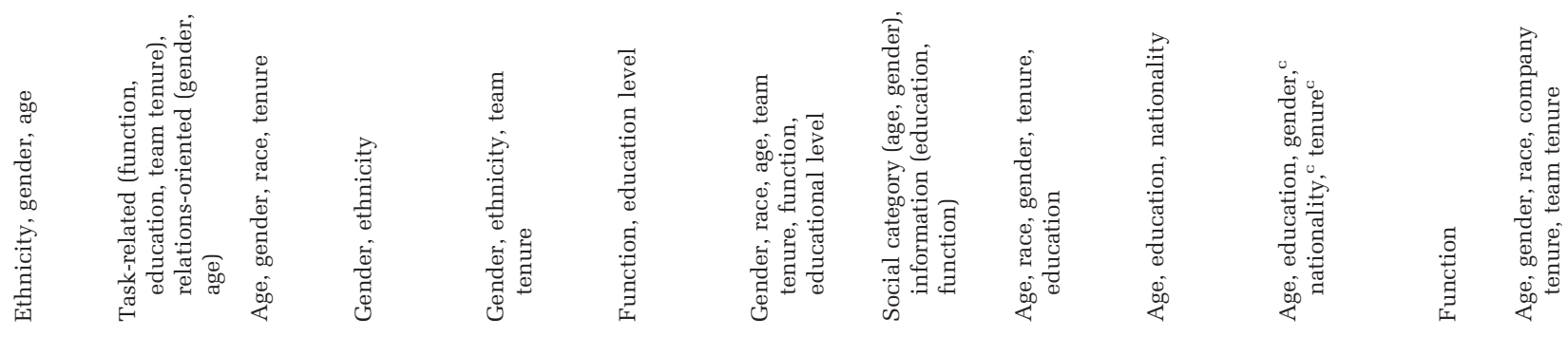

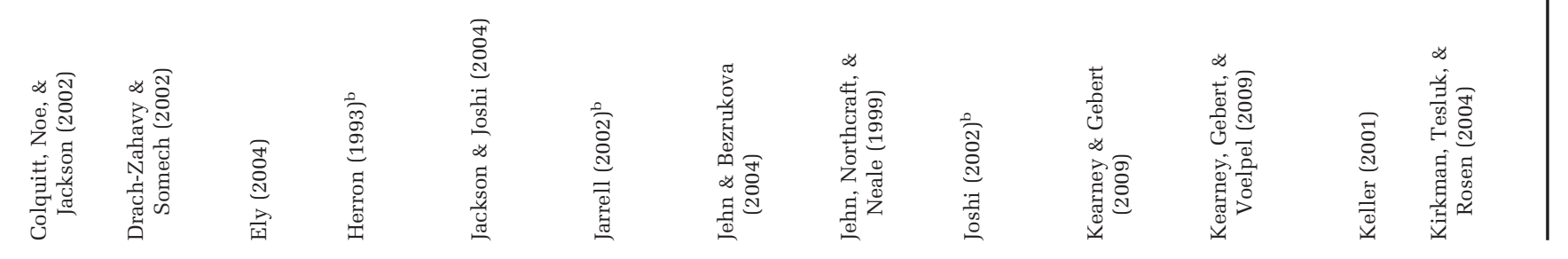




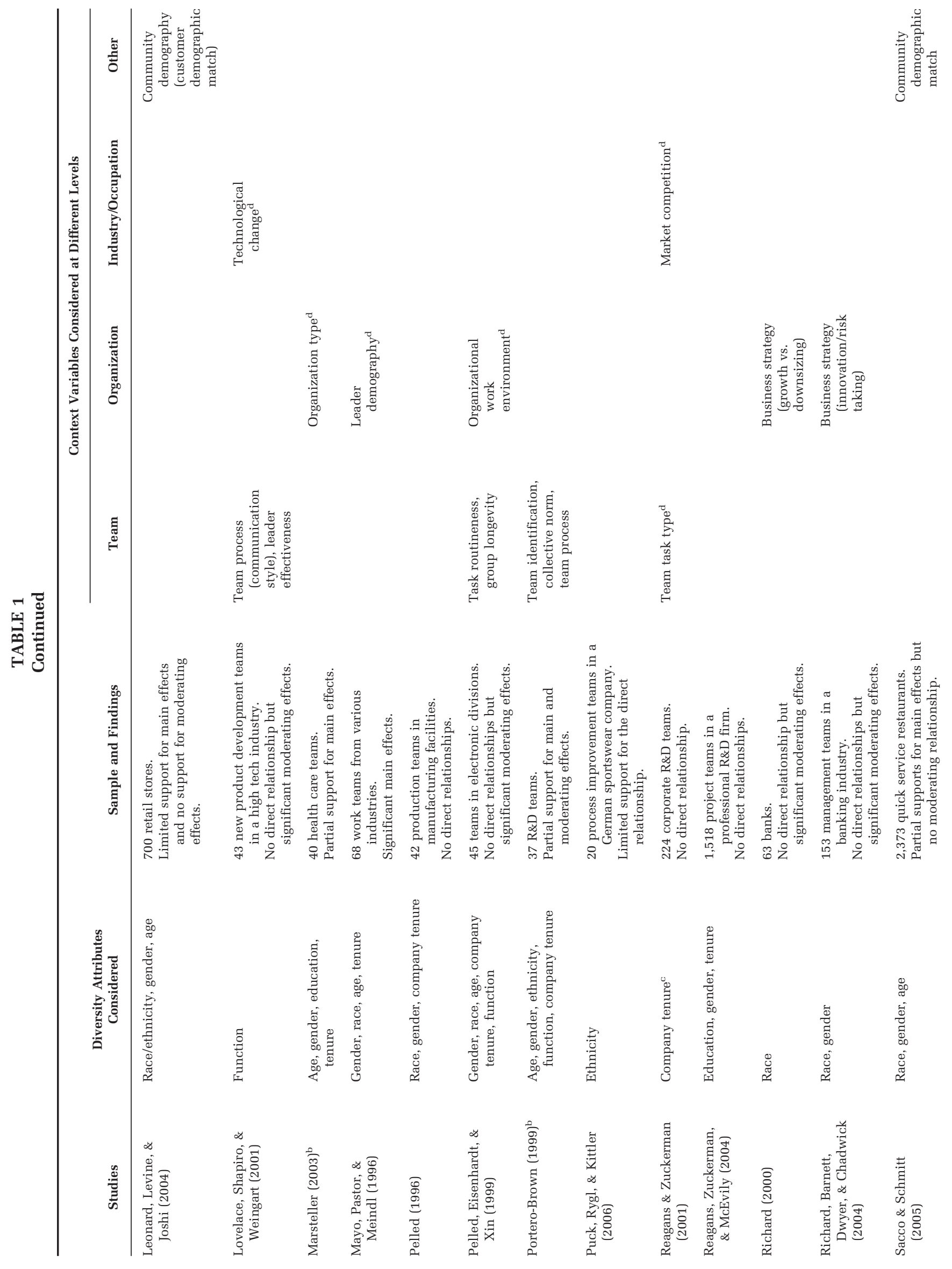



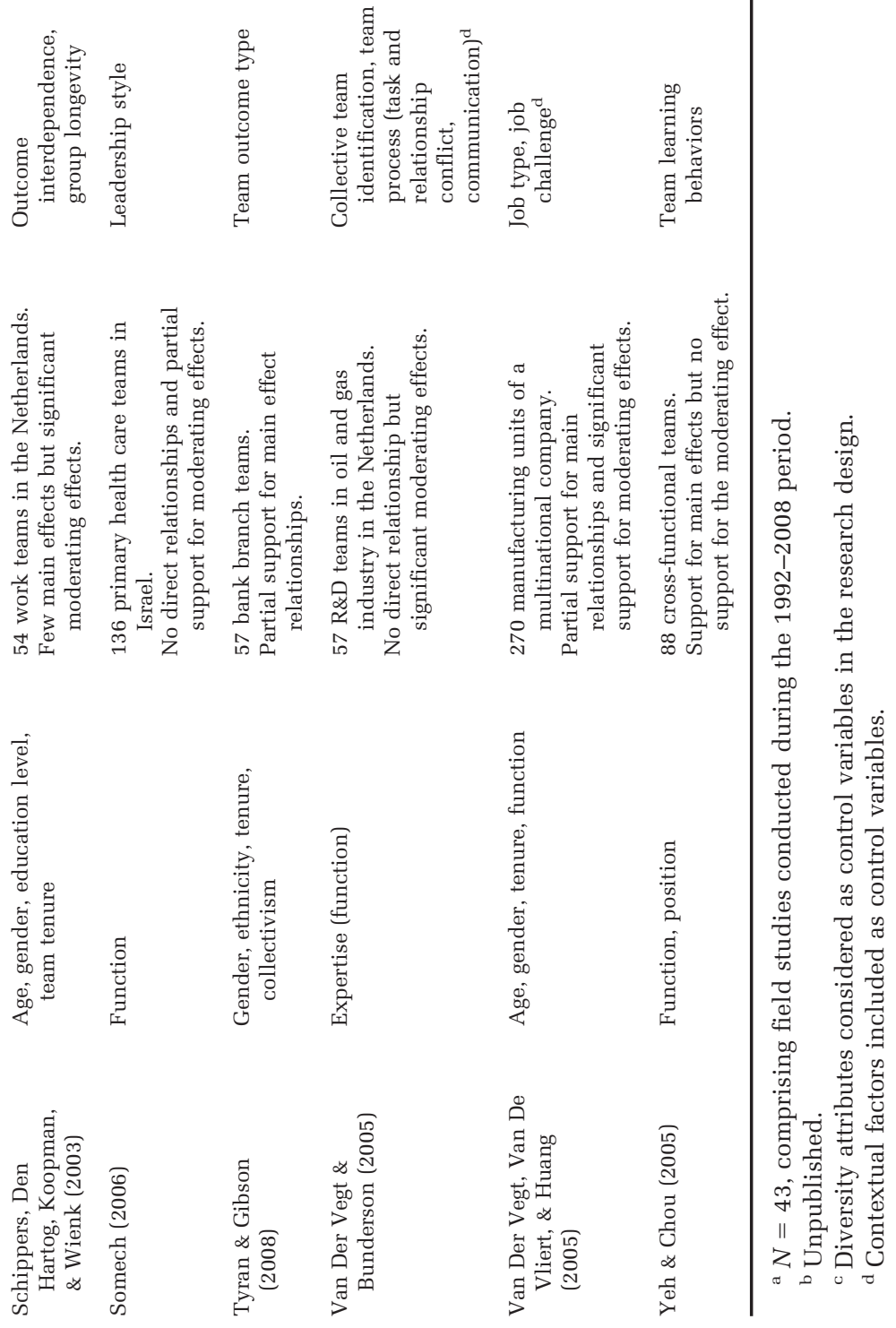
diversity context. On a practical note, information regarding occupational and industry setting was available from most study descriptions. Additionally, publicly accessible databases provide a wealth of objective information regarding the occupational and industry contexts in which teams are embedded. Therefore, we focus on industry setting and occupational demography as contextual factors that provide a comprehensive understanding of a team's macrolevel context and could potentially account for the mixed findings reported.

The nature of a team's task can have a significant influence on the extent to which team members are interdependent in terms of goals and task outcomes (see Ilgen, Hollenbeck, Johnson, \& Jundt, 2005; LePine, Hanson, Borman, \& Motowidlo, 2000). As the review above suggests, team-level contextual variables have received the most attention in past research. Social categorization theory would suggest that aspects of a team's task can minimize the salience of diversity attributes by reinforcing a common group identity or by placing demands on the team's diverse cognitive resource base (Gaertner \& Dovidio, 2000; Jehn et al., 1999). Information processing theory would suggest that the nature of tasks would place requirements on a team's cognitive resource base with implications for the salience of diversity attributes within the team (Jehn et al., 1999; Williams \& O’Reilly, 1998). Our review also indicated that information regarding aspects of teams' tasks, such as team interdependence and team type (i.e., short-term versus long-term), was more consistently available across studies. Therefore, we chose to focus on task interdependence and team type as aspects of team-level context. Ultimately, we sought to examine the effects of conceptually distinct contextual variables that together provide a comprehensive picture of context at the team level. In the subsequent sections, we discuss in greater detail how these aspects of occupational, industry, and team-level context may shape the performance outcomes of both task-oriented and relations-oriented team diversity.

\section{A CONTEXTUAL FRAMEWORK FOR TEAM DIVERSITY RESEARCH}

\section{Occupational Demography}

In the United States, workers are classified into occupational categories based on work performed, skills, education, training, and credentials. Some occupations are found in just one or two industries (e.g., post office clerks); however, many occupations are found in a large number of industries (e.g., auditors, accountants, software developers, net- work analysts). Thus, the term "occupation" refers to this collective description of a number of individual jobs performed, with minor variations, in many establishments (U. S. Bureau of Labor Statistics, 2007). A significant body of sociological research shows that occupation-level demographic composition can have important implications for gender-based and ethnicity- or race-based diversity in organizations (for a review, see Reskin et al. [1999]). We propose below that occupational demography serves as a situational setting that can enhance the effects of relations-oriented diversity and minimize the effects of task-oriented diversity on team performance.

Considerable research on stereotype formation enables us to specify the psychological processes by which an occupational demography can influence diversity dynamics within teams. This research suggests that stereotypes, which emerge in response to environmental factors-such as differences in social roles (Eagly, 1995) and in power (Fiske, 1993)—and as a means to justify the status quo (Jost \& Banaji, 1994; Sidanius, 1993), result in categorization-based responses toward targeted groups (Allport, 1954). When a single demographic group dominates an occupation, negative stereotype-based categorization processes against underrepresented groups are likely (Fiske, 1993; Reskin et al., 1999). Once categorization-based processes are invoked, additional information regarding targeted group members is filtered out, and individuating processes are blocked (Allport, 1954; Brewer, 1988). In diverse teams, when the environment primes negative stereotypes against specific demographic groups, these categorization-based processes are likely to influence interactions. In work environments, where stereotypes are less salient, individuating information regarding demographically dissimilar individuals is likely to be cognitively acceptable and result in more positive interactions (see Larkey, 1996). Integrating these perspectives, we propose that in occupational settings dominated by a single demographic group, it is likely that stereotypic reactions against underrepresented groups will be triggered (Fiske, 1993; Reskin et al., 1999). These reactions result in categorization-based processes that hinder effective group interactions, with negative performance consequences (Larkey, 1996). These categorizationbased processes are less likely in demographically balanced occupational settings.

A rich body of research on the age, race, and gender typing of jobs corroborates our argument that the demographic attributes of a job category or occupation are associated with job stereotypes that may trigger social categorization processes based 
on these demographic attributes (Eagly \& Steffen, 1984; Perry, 1997). For example, consider the maledominated occupational category of production engineers. On the basis of the research reviewed above, we would surmise that female engineers (an underrepresented group) are likely to be targets of negative stereotypes (e.g., "women are less technically competent") enhancing the salience of gender as a basis for categorization when men and women work together in a production team (Eagly \& Steffen, 1984; Ely, 1994, 1995). We propose that gender diversity is likely to have negative performance effects in this setting. In a more gender balanced occupational setting, such as postsecondary science teaching, on the other hand, this research suggests that gender may not emerge as a salient basis for categorization within a team of teachers working on organizing a school science fair. In this setting, gender diversity is less likely to have a negative influence on team performance. A similar argument can be made with regard to the effects of occupational race/ethnic composition on the performance outcomes of race/ethnicity-based diversity in teams (Reskin et al., 1999).

Regarding the effects of occupational age composition, a significant body of research suggests that negative stereotypes against older workers are fairly prevalent and can have detrimental consequences for these workers (Fiske, Cuddy, Glick, \& $\mathrm{Xu}, 2002$; Rosen \& Jerdee, 1977; see Shore and Goldberg [2005] for a recent review). Although older workers may experience more unfavorable job outcomes overall, research also indicates that the age composition of a job context can influence performance ratings and advancement potential for older employees. This research suggests that older workers may face more unfavorable outcomes in occupations with fewer older workers (Cleveland, Festa, \& Montgomery, 1988; Cleveland, Montgomery, \& Festa, 1984). In view of this research, we would propose that among, for example, software programmers (an occupation dominated by younger workers), older programmers may be targets of negative stereotypes (e.g., viewed as less skilled or motivated); the implications of age diversity-based outcomes would thus be negative when older and younger team members collaborate on a joint software development project. In work settings with a higher proportion of older workers (for instance, among welfare service workers or post office clerks), these workers are less likely to face stereotypes and discrimination (Shore \& Goldberg, 2005). In these settings, categorization-based effects based on age are less likely to disrupt groups' functioning.

To date, diversity research has not addressed the role of occupational demography in shaping performance outcomes within diverse teams. At the firm level, Frink et al. (2003) found that an inverted U-shaped relationship between gender composition and performance was only observed in genderbalanced occupational settings and not in maledominated settings. The authors noted that these findings may reflect the inability of organizations in male-dominated contexts to capitalize on the benefits of gender diversity (Frink et al., 2003). Although the researchers had not accounted for this contextual factor in their theoretical framework, hypotheses, or study design, they discussed the importance of occupational demography in explaining their findings.

Cumulatively, the research perspectives discussed above suggest that in occupational settings dominated by a single demographic group, diverse teams may face performance losses primarily for two reasons. First, these teams may perform suboptimally because the work context enhances stereotyping and bias against underrepresented demographic groups that triggers social categorization based on these attributes within the teams (DiTomaso, Post, \& Parks-Yancy, 2007; Skaggs \& DiTomaso, 2004; Van Knippenberg et al., 2004). Second, in these settings, teams with higher proportions of underrepresented group members (e.g., women or ethnic minorities) may be valued less and receive poorer performance ratings or access to resources, which is likely to impact subjective or objective performance outcomes (Baugh \& Graen, 1997; Hultin \& Szulkin, 1999; Joshi, Liao, \& Jackson, 2006). In view of these considerations, we proposed that occupational demography will moderate the relationship between relations-oriented diversity and team performance and tested specific aspects of that general relationship metaanalytically with the following:

Hypothesis 1a. Occupational gender composition moderates the negative effect of team gender diversity on performance. The negative effect of gender diversity on performance is weaker in gender-balanced settings.

Hypothesis 1b. Occupational race/ethnic composition moderates the negative effect of team race/ethnic diversity on performance. The negative effect of race/ethnic diversity on performance is weaker in racially/ethnically balanced settings.

Hypothesis 1c. Occupational age composition moderates the negative effect of team age diversity on performance. The negative effect of 
age diversity on performance is weaker in relatively age-balanced settings.

So far we have argued that occupational demography creates a context that may enhance or minimize categorization-based processes in work groups. Our arguments raise the possibility that occupational demography will moderate the relationship between task-oriented diversity and team performance as well. We surmise that when a single demographic group dominates an occupation, relations-oriented diversity may be correlated with task-oriented diversity. For example, white men may be more tenured and have a specific educational background. In these settings, individuals' task-relevant contributions may be confounded with their demographic attributes (Berger, Fisek, Norman, \& Zelditch, 1977) so that any positive outcomes of task-oriented diversity on performance may also be mitigated. Researchers have also noted that when the negative effects of categorizationbased diversity are salient, information processing in groups is disrupted (Van Knippenberg et al., 2004). Some studies have shown that when relations-oriented diversity is associated with greater conflict, task-oriented diversity is also less likely to have positive outcomes (Homan \& Van Knippenberg, 2003; Jehn et al., 1999). In view of these perspectives, to account for the possibility that occupational demography may have implications for the outcomes of task-oriented diversity, we propose the following broad hypothesis:

Hypothesis 1d. Occupational demography moderates the positive effect of task-oriented diversity on team performance. The effects of task-oriented diversity are stronger in more balanced settings.

\section{Industry Setting}

Industry settings refer to fairly specific business environments in which teams are nested that may have important implications for team diversity dynamics that go over and above the occupational effects discussed above (Batt, 2002; Datta, Guthrie, \& Wright, 2005). Porter's (1980) analysis identifies factors such as customers, suppliers, and regulatory groups that vary by industry and pose varying contingencies for firms. Contingency theory suggests that these industry factors provide firms with opportunities as well as challenges for utilizing key organizational resources to enhance performance (Burns \& Stalker, 1961; Drazin \& Van de Ven, 1985; Lawrence \& Lorsch, 1967; Porter, 1980). Drawing on this perspective, a significant body of strategic management research has identified industry con- text as a key contingency that influences the relationship between organizational processes/practices and performance outcomes (see Combs, Lieu, Hall, and Ketchen [2006] for a meta-analysis). Industry-level context has received some, albeit limited, attention in past diversity research (e.g., Ancona \& Caldwell, 1992; Lovelace et al., 2001; Reagans \& Zuckerman, 2001). On the basis of strategic management perspectives and in line with our conceptualization of context, we considered whether contingencies associated with three specific contexts-service, manufacturing, and high technology - may serve as situational enhancers or minimizers of diversity effects on performance outcomes. Together, these three industrial settings incorporate a bulk of the research settings considered in past diversity research.

Service industries, defined as customer-oriented industries that require front-line customer interaction and engagement, include retail trade, hospitality, and education (U.S. Census Bureau, 2002). Relative to manufacturing industries, service industries are characterized by more frequent and closer interactions with customers and a greater emphasis on discretionary behavior that can manifest directly in performance outcomes such as sales, customer satisfaction, and customer retention (Datta et al., 2005). Researchers have argued that increasing demographic attribute-based diversity can enhance a firm's "market competence," which is a form of competitive advantage in the service industry (Richard et al., 2007). Consider as an example that a retail store with a diverse group of store employees is more likely to attract diverse customers and thereby also more likely to have strong store sales. On the other hand, a competing store that is unable to enhance employee diversity to attract customers and increase market share is likely to perform poorly in comparison. On the basis of these considerations, we would expect that aspects of service settings such as direct customer contact and higher levels of discretionary behaviors would serve as situational enhancers of relationsoriented diversity effects on performance. In the service industry, since these aspects of diversity can be considered as a form of market competence, we propose that any negative effects of gender, race, and age diversity are likely to be reversed.

Manufacturing industries are based on the fabrication, processing, or preparation of products from raw materials and commodities. These industries are typically highly capital-intensive and include automobile manufacturing, chemical manufacturing, and paper and wood manufacturing (U. S. Census Bureau, 2002). In contrast to service industry firms, manufacturing firms rely more on plant and 
equipment, technology, and raw materials to achieve business goals (Quinn, Anderson, \& Finkelstein, 1996). Because manufacturing relies more on physical capital and equipment and less on direct customer-based interactions, we would expect diversity attributes to be less likely to directly impact performance in this setting (Richard et al., 2007). Further, Combs and colleagues (Combs, Hall, \& Ketchen, 2006) noted that manufacturing industries are more likely than service industries to implement total quality management techniques, regular training, and formalized human resource (HR) practices because of the need to monitor employees and to develop their knowledge, skill, and ability to utilize expensive and sometimes dangerous machinery. Consider, as an example, the automobile manufacturing industry, which has implemented a number of total quality management techniques involving team-based interventions and undertaken regular training for employees. These attributes of the automobile industry may serve to buffer any direct effects of team diversity. Thus, we surmise that aspects of manufacturing settings, such as reliance on machinery and HR practices that involve greater monitoring of employee behavior, may act as situational minimizers of diversity effects on performance outcomes.

High-technology industries follow invention and innovation in business strategy and compete in global and short-cycle product-markets (cf. Milkovich, 1987). In contrast to service and manufacturing industries, these industries rely more heavily on intellectual capital and invest significantly more in research and development (Organisation for Economic Cooperation and Development, 2006). Industries such as information technology, biomedical technology, telecommunication, and data services are included in this category. Researchers have begun to examine this particular setting as a distinct context framing firm practices and outcomes (Collins \& Smith, 2006). This research has suggested that employers in this setting are also likely to adopt commitment-based practices aimed at recruiting and retaining highly skilled employees, which can create a climate fostering knowledge exchange and combination (Collins \& Smith, 2006). These situational contingencies may enhance taskoriented diversity effects. Relative to service and manufacturing settings, given contingencies such as rapidly changing technology, reliance on intellectual capital, and a need for creativity and innovation in a dynamic environment, we would expect task-oriented attributes that form a team's cognitive resource base to significantly impact performance outcomes in this setting.

Although a significant body of research on top management teams has examined industrial environment as a relevant influence on the outcomes of diversity (e.g., Hambrick et al., 1996; Hambrick \& Finkelstein, 1987; Keck, 1997), research on lowerlevel teams has rarely taken this contextual factor into account. In general, top management team research suggests that industry attributes, such as rate of technological change, munificence, and environmental uncertainty, can enhance the salience of diversity in top management teams in relation to firm performance (see Carpenter, Geletkanycz, and Sanders [2004], and see Hambrick and Finkelstein [1987] for a review). Richard and colleagues (2007) examined whether industry (service versus manufacturing) moderated the relationship between racial diversity and firm performance in a sample of over 800 large U.S. companies; in support of the propositions, results indicated that the relationship between racial diversity and firm performance was stronger in service than in manufacturing firms (Richard et al., 2007).

On the basis of the theoretical and empirical perspective detailed above, we would expect the three distinct industrial settings to impose varying contingencies on diversity outcomes. In service settings, customer-based contingencies may enhance positive performance outcomes of relations-oriented diversity. In manufacturing settings, a reliance on physical equipment and standardized practices to monitor employee behavior may minimize any direct performance outcomes of diversity; and in hightechnology settings, technological and intellectual capital-based contingencies may enhance positive effects of task-oriented diversity. Thus, we propose that industry setting moderates the relationship between relations- and task-oriented diversity and team performance. Specifically:

Hypothesis 2a. Relations-oriented diversity is likely to have a positive effect on performance in service industries. In manufacturing and hightechnology settings, relations-oriented diversity is less likely to have a significant effect on performance.

Hypothesis $2 b$. The positive effect of task-oriented diversity on performance is stronger in high-technology industries than in manufacturing and service settings.

\section{Team-Level Diversity Context}

We propose below that specific team characteristics-team interdependence and team type-constitute a team-level diversity context that can enhance or minimize the direct effects of relations- 
oriented and task-oriented diversity on team performance.

Team interdependence. Teams display varying levels of interdependence based on their tasks, goals, and outcomes. Task interdependence is defined as the extent to which team members rely on each other to complete their task (Shea \& Guzzo, 1987). In highly task interdependent teams, team members engage in both sequential and reciprocal exchanges to accomplish the team tasks; in less task interdependent teams, team members' independent contributions are aggregated to accomplish the team tasks (Saavedra, Earley, \& Van Dyne, 1993; Thompson, 1967; Van de Ven, Delbecq, \& Koenig, 1976). Teams may also vary on goal and outcome interdependence. Goal interdependence refers to the extent to which a team as a whole has a collective goal. Outcome interdependence refers to the extent to which team members are interdependent in terms of rewards and feedback. These aspects of interdependence tend to be highly correlated and therefore researchers have suggested combining them into an overall team interdependence construct (Gully, Incalcaterra, Joshi, \& Beaubien, 2002).

Social categorization theory would predict that higher outcome and goal interdependence is likely to unite team members to work toward a common goal and motivate them to cast aside differences (Gaertner \& Dovidio, 2000). Task interdependence may facilitate intergroup contact conducive to reducing categorization-based processes in teams (Pettigrew, 1998). Team interdependence has received considerable attention as a moderating influence in team diversity research. For example, Schippers and colleagues (2003) found that outcome interdependence reinforces common group goals that can counteract the negative effects of diversity, so that highly outcome-interdependent teams with high levels of diversity display more task-related discussions and communication than highly diverse teams with low outcome interdependence. Jehn and colleagues also reported that demographic diversity was positively associated with satisfaction and commitment when task interdependence was high (Jehn et al., 1999). Other research has also supported this pattern of findings (e.g., Van der Vegt \& Janssen, 2003). We would expect that high interdependence creates a context for elaboration-based processes within a team and thus that the outcomes of task- and relationsoriented diversity may be more positive or less negative when the level of interdependence is high. Hence, we propose:

Hypothesis 3. Team interdependence moderates the relationship between task- and rela- tions-oriented diversity and team performance. The positive effect of task-oriented diversity on team performance is stronger among highly interdependent teams. The negative effect of relations-oriented diversity on team performance is weaker among highly interdependent teams.

Team type. The durability of a team's membership-that is, whether the team has been assembled to accomplish a short-term goal or whether it is instead a stable and permanent unit in an organization-is likely to have consequences for interpersonal interactions among diverse team members. Task-related contingencies are likely to differ in short- and long-term teams. In short-term teams, greater urgency may surround goals and missions. On the other hand, in long-term teams, task requirements may be more stable, and distribution of tasks and roles may also be more clearly defined (De Dreu \& Weingart, 2003). Another dimension along which these teams are likely to differ is the longevity of team membership. The members of shortterm teams likely have shorter tenure, than the members of long-term teams. ${ }^{3}$ Thus, temporal dynamics are also likely to vary in these two types of teams.

Some studies that have examined temporal influences on team diversity outcomes have shown that the length of time team members spend together may diminish the salience of visible aspects of diversity and enhance the salience of attitudinal or value-based aspects of diversity (Harrison et al., 1998; Harrison, Price, Gavin, \& Florey, 2002). Schippers and colleagues (2003) found that over a longer duration, highly diverse teams were less likely to display elaboration-based processes. In the short run, however, diverse teams engaged in more task-relevant debates and discussions that had positive consequences for team performance. The authors noted that in long-standing diverse teams, team members may attribute conflicts to relational differences, and the motivation and willingness to resolve differences through greater communication may erode over time. In the short term, on the other hand, the members of highly diverse teams are more likely to communicate across differences to accomplish the teams' tasks (Schippers et al., 2003). Corroborating this finding, Watson, Johnson, and Merrit (1998) also found that demographic di-

\footnotetext{
${ }^{3}$ Although team tenure or longevity could also be important variables to consider, our review indicated that these variables were sparsely reported in extant research and we were, therefore, unable to include these in the present study.
} 
versity was negatively associated with outcomes over time. We propose, on the basis of this empirical research, that in short-term teams, urgency surrounding the accomplishment of the tasks may require team members to overlook differences and aim at utilizing diversity based on task-relevant dimensions. Since short-term teams are also associated with shorter team tenure, team members may be less likely to attribute task-based differences to deeper attitudinal or personality-based differences (Harrison et al., 1998; Schippers et al., 2003). In long-term teams, divisions based on diversity attributes may become more entrenched and self-reinforcing, so that conflicts and differences based on relations-oriented attributes have a more debilitating impact on team performance (Schippers et al., 2003; Watson et al., 1998). In view of these considerations, we meta-analytically tested the following:

Hypothesis 4. Team type moderates the relationship between task- and relations-oriented diversity and team performance. The positive effect of task-oriented diversity is stronger in short-term teams than in long-term teams. The negative effect of relations-oriented diversity is stronger in long-term teams than in short-term teams.

\section{METHODS}

\section{Literature Search}

We employed multiple search techniques to identify prior empirical research that examined the relationship between work team diversity and performance. First, we searched the computerized databases PsycINFO, ABI/Inform, and SocIndex using keywords such as "team/group diversity," "team/ group composition," "team/group performance," and "team/group effectiveness" as well as search terms associated with specific team diversity attributes (e.g., "gender," "race/ethnicity," "age," "tenure," "education," and "functional background diversity"). Second, the electronic search was supplemented by a manual search of 19 major journals, including Academy of Management Journal, Administrative Science Quarterly, Journal of Applied Psychology, Personnel Psychology, Organization Science, and Journal of Organizational Behavior, and others considered the most highly cited journals in the field of management (see Gomez-Mejia \& Balkin, 1992). Third, we also consulted the reference lists from previous reviews on this topic, including both narrative (Harrison \& Klein, 2007; Jackson et al., 2003; Milliken \& Martins, 1996; Van Knippenberg \& Schippers, 2007; Williams \&
O'Reilly, 1998) and quantitative (Bowers et al., 2000; Horwitz \& Horwitz, 2007; Webber \& Donahue, 2001) reviews. Finally, in an effort to identify relevant unpublished studies, we searched ProQuest Digital Dissertations and conference proceedings for the annual meetings of the Academy of Management and the Society of Industrial and Organizational Psychology for the previous five years. Researchers in related areas were also contacted to obtain current and unpublished studies that might fit our criteria for inclusion.

Since this study concerned detecting the moderating effects of several contextual variables embedded at multiple levels, we focused only on studies that had been conducted in field settings where these variables were likely to influence diversity outcomes. We did not include studies that relied on student samples, were conducted in laboratory settings, or involved simulated tasks or tasks in artificial environments. Although these types of studies are of great value in theory development, for the purposes of this research we were interested in identifying contextual moderators influencing diversity outcomes in naturally occurring, intact work teams in business settings. Research suggests that these types of teams differ substantively from laboratory teams (e.g., McGrath, 1984). From an initial set of 95 field studies conducted in organizational settings, we applied the following additional criteria to select articles for our meta-analysis. First, although diversity research has often been conducted at multiple levels of analysis, we restricted the present meta-analysis to the team level. For a study to be included in the meta-analysis, both diversity and performance had to be measured at the team level. Second, team diversity variables had to include either relations-oriented diversity attributes (race/ethnicity, gender, or age) or task-oriented diversity attributes (education, functional background, or organizational tenure) pertinent to our theoretical arguments. Third, we also excluded studies that examined top management teams $(n=47)$ because outcomes for such teams were often measured at the firm level (e.g., as organizational financial performance), and top management teams were generally considered as operating under different dynamics than lowerlevel general work teams in organizations (e.g., Hambrick \& Mason, 1984; Webber \& Donahue, 2001). Furthermore, team effectiveness models also suggest that performance is a proximal outcome of team composition among general work teams; this assumption may not hold among top management teams (Hackman, 1987). Finally, a study had to report sample sizes and an appropriate statistic (e.g., mean and standard deviation, chi-square, $t, F$ ) 
that allowed the computation of a correlation coefficient with the formula provided by Hunter and Schmidt (1990: 272). Based on these criteria, the final data set included 8,757 teams from 39 studies conducted between 1992 and 2009, yielding a total of 117 effect sizes. The data included in the final analyses represent approximately twice the number of effect sizes and three times the number of teams included in past published meta-analyses on this topic (e.g., Webber \& Donahue, 2001).

\section{Coding of Studies}

Our initial coding scheme was based on operationalization of team characteristics (team interdependence and team type) and research setting (occupational and industry setting). Using this scheme, each author and two additional raters independently coded a random selection of five articles; initial interrater agreement ranged between 75 and 94 percent. To resolve disagreements, we went back to the studies and reached consensus through discussion. From this discussion, we developed a detailed set of decision rules and used them to code an additional seven articles. Interrater agreement was almost 100 percent for these articles. The authors then coded the remaining articles using the decision rules we had developed.

\section{Measures}

Team diversity. Drawing on past research (e.g., Jackson et al., 1995; Webber \& Donahue, 2001), we classified diversity attributes into two categories: relations-oriented (race/ethnicity, gender, and age) and task-oriented (organizational tenure, education, and functional background). In the studies included in the analyses, categorical diversity attributes were measured using Blau's (1977) index or Teachman's (1980) entropy measure; Allison's (1978) coefficient of variation was used for continuous variables such as age and tenure. Because measures based on "faultlines" (hypothetical lines splitting a group into attribute-based subgroups [Lau \& Murnighan, 1998: 328; 2005: 645]) were used less frequently and in some cases combined demographic and task-oriented attributes, these were not included in the present analysis. In general, the operationalization of relations- and taskoriented diversity in this study is theoretically driven and consistent with past research. Our initial review also indicated that the diversity attributes included in this meta-analysis were the most commonly studied variables in past research. However, since the measurement of diversity attributes in studies involved in the sample predates recent reconceptualizations (e.g., Harrison \& Klein, 2007), we were unable to incorporate these newer directions in this study.

Team performance. Measures of team performance included financial and operational measures (e.g., sales, productivity), product quality/ quantity, team innovation, supervisor ratings of team performance/effectiveness, and self-ratings by team members. Most studies provided objective team performance measures or ratings by supervisors. For subjective performance measures, reliabilities of measurement instruments were recorded whenever reported. In those cases in which no reliabilities were reported, we took the average reliability of the same variable from all other studies. The average reliabilities were .82 for subjective performance measures. To maintain the statistical independence of the data set, when multiple measures for team performance were available, we included only the most objective external measure; when no other source was available, we relied on team members' own assessments of their performance. In a study measuring multiple dimensions of team performance (e.g., its quality and quantity), we calculated a composite effect by averaging each correlation coefficient.

Occupational demography. We relied on the archival data from the Labor Force Statistics of the Current Population Survey (U.S. Bureau of Labor Statistics, 2006) to obtain definitions and statistics of occupational categories. Initially we coded the research settings (based on sample descriptions) of studies included in the meta-analysis using Bureau of Labor Statistics (BLS) definitions; then we obtained the occupational gender, race/ethnicity, and age composition data from the BLS data set and assigned this demographic composition to the occupations included in the studies. For example, if a study's respondents were described as members of production teams from multiple electronics manufacturing firms, we obtained data on electrical, electronics, and electro-mechanical assemblers' gender, ethnicity, and age from the BLS website and used them to measure occupational demography $(n=16)$. For teams that included multiple occupations (e.g., cross-functional product development teams consisting of engineers and production supervisors), we found demographic data for each occupational category involved in a team and then calculated a composite value by averaging the demographic information on all participating occupations from the BLS data set $(n=8)$. In aggregating data over multiple occupational categories, we were careful not to include studies that incorporated occupations that were differently skewed demographically. For example, when a research sam- 
ple involved multiple occupations in single teams-combining, say, the white-male-dominated occupation of network analyst and the relatively balanced occupation of insurance underwriter or HR professional (Campion, Papper, \& Medsker, 1996)—we performed no aggregation and excluded the study from this set of analyses. Moreover, when studies were unclear about the samples used, had non-U.S. samples for which data were not available, or had samples with multiple types of teams, we also excluded them from the analyses.

Among the studies included in these analyses, the occupational percent female ranged from 20.6 to 73.4 percent, and the occupational percent ethnic minority (i.e., nonwhite) ranged from 15.7 to 37.6 percent. If either of these percentages was below the overall mean for all U.S. occupations (i.e., 46.3 percent for female composition and 29 percent for minority composition), the occupational setting was characterized as "majority male" or "majority white" for the purposes of categorical analyses. Occupational settings with above-average percents female or minority were categorized as "balanced" settings. In our sample, we did not encounter enough study settings that could be categorized as majority female or majority ethnic minority; therefore, we were unable to test the effects of diversity in these settings. Occupational age composition data were based on the information provided by the BLS, which offers data on four age categories by occupation. We considered an occupation as "majority younger worker" if the proportion of older (over 55 years) workers in that occupation was lower than the average across occupations (i.e., 18\%) and as "balanced" if the proportion of older workers was above the average across occupations.

Industry setting. Industry was also coded whenever it was reported and whenever the research setting or sample was described. Following strategic management research (e.g., Collins \& Smith, 2006; Datta et al., 2005) and drawing from the detailed industry descriptions based on the North American Industry Classification System (NAICS; U. S. Census Bureau, 2002), we classified industries examined in previous research into three broad categories: service, manufacturing, and high technology. Service industries in the sample included wholesale/retail trade, finance/insurance, health care, educational service, moving/ transportation, and government service; manufacturing industries included automobile manufacturing, paper and wood manufacturing, textile manufacturing, oil and gas, chemical product manufacturing, and general equipment manufacturing. High technology included semiconductor/electronics, information processing, telecommunication, and professional R\&D services. Studies that included samples from multiple industry settings were excluded from our analyses $(n=5)$.

Team interdependence. Drawing on conceptual definitions of interdependence presented in previous research (e.g., Campion, Medsker, \& Higgs, 1993; Saavedra et al., 1993; Shea \& Guzzo, 1987), we determined team interdependence using three separate ratings for task, goal, and outcome interdependence. Each dimension was rated on a scale ranging from 1 to 3 (low, moderate, and high) and averaged to provide a composite score of overall team interdependence. Low-interdependence teams included, for example, production or sales teams with sequentially related activities or individualbased goals and rewards; cross-functional R\&D teams whose members frequently exchanged ideas and shared common goals were deemed highly interdependent.

Team type. We also coded team type based on the length of time a team was expected to exist (Schippers et al., 2003). Two broad categories, short-term and long-term, were used. Cross-functional project teams existing for a limited period were considered short-term teams, for example. Permanent work teams and general work teams existing for longer than two years were generally considered long-term.

\section{Meta-Analytic Techniques}

We used Hedge and Olkin's (1985) meta-analytic procedures to analyze the data. Zero-order correlations between work team diversity and performance were taken or calculated from each study and corrected for measurement error. Following Hunter and Schmidt's (1990) formula, we also corrected the correlations for unreliability using the artifact distributions for subjective team performance measures. We calculated weighted mean correlations by adopting the inverse variance weights and applying Fisher's $Z$ transformation procedures (Hedge \& Olkin, 1985; Lipsey \& Wilson, 2001). Ninety-five percent confidence intervals were calculated around the sample-weighted correlation as a measure of accuracy of the effect size (Whitener, 1990). The failsafe $k$ was also calculated to identify the number of "file drawer" (unknown) studies of the same relationship with a true correlation of zero needed to widen the reported confidence interval enough to include zero (Orwin, 1983; Rosenthal, 1979). 
Heterogeneity of effect sizes. To determine whether effect sizes were consistent over the studies reviewed, we tested the homogeneous distribution of the effect sizes by calculating the $Q$ statistic (Hedge \& Olkin, 1985). A significant $Q$ indicates the likelihood of moderators that explain variability in correlations over studies (Lipsey \& Wilson, 2001). We also examined the potential impact of outliers by calculating the sample-adjusted meta-analytic deviancy statistic suggested by Huffcut and Arthur (1995). Three outliers were identified by use of this statistic, but a detailed review of the potential outliers revealed no problematic correlations, so these were not eliminated from the analyses.

Moderator analysis. We conducted detailed moderator analyses to determine whether multilevel contextual variables were related to the heterogeneity of effect sizes (Hedge \& Olkin, 1985; Lipsey \& Wilson, 2001). The logic of the categorical model moderator test is analogous to analysis of variance (ANOVA). Calculating the categorical models results in (1) the between-group goodnessof-fit statistic $Q_{\mathrm{B}}$, which has an approximate chisquare distribution with $p-1$ degrees of freedom, where $p$ is the number of groups, and (2) the within-group goodness-of-fit statistic $Q_{\mathrm{w}}$, which has an approximate chi-square distribution with $m-1$ degrees of freedom, where $m$ is the number of effect sizes in the group. That is, $Q_{\mathrm{B}}$ is analogous to a main effect in an ANOVA, and $Q_{\mathrm{w}}$ indicates homogeneity within each group in an ANOVA. In the present analysis, as recommended in previous research on this topic (e.g., Webber \& Donahue, 2001), we used a $Q_{\mathrm{B}}$ statistic to test whether the categorical moderator model was statistically significant and then examined each subgroup within the sample by testing the confidence intervals for statistical significance and by comparing the effect sizes across subgroups whenever possible. For the continuous moderators (i.e., occupational percent female and occupational percent minority), weighted least squares (WLS) regression was also used, as suggested by Hedge \& Olkin (1985). This procedure involves weighting each observed effect size by the inverse of its variance, as with formulae for weighted means and confidence intervals (Lipsey \& Wilson, 2001). Using such an approach avoids the artificial categorization of continuous moderating variables. Two indexes assessing the overall fit of the weighted regression model can be calculated: a $Q$ attributable to the regression and a $Q$ error or residual (denoted as $Q_{\mathrm{R}}$ and $Q_{\mathrm{E}}$, respectively, and both distributed as a chisquare). $Q_{\mathrm{R}}$ is analogous to an $F$ for a regression model and, if significant, indicates that the re- gression model explains significant variability in the correlations of the relationship between team diversity variables and team performance (Lipsey \& Wilson, 2001). ${ }^{4}$

\section{RESULTS}

\section{Main Effects: Work Team Diversity and Performance}

Using the meta-analytic techniques described above, we tested the main effects of work team diversity on performance outcomes as well as the moderating effects of contextual factors embedded at multiple levels. Table 2 presents the main effect results. We first examined the correlations between all types of diversity and performance and obtained a near-zero, nonsignificant result $(r=-.01, k=$ $117,95 \%$ CI $=-.02$ to .00). This initial result corroborated past meta-analytic findings (e.g., Webber \& Donahue, 2001). We then conducted separate analyses for relations- and task-oriented diversity and found a different pattern of results for each type of diversity. For relations-oriented diversity, we found a very weak negative but significant relationship with performance $(r=-.03, k=69$, $95 \% \mathrm{CI}=-.05$ to -.02 ). The relationship between task-oriented diversity and performance was also very weak but positive and significant $(r=.04, k=$ $48,95 \%$ CI $=.02$ to .06). The failsafe $k$ 's in Table 2 suggest that, although the effect sizes are very small, at least 118 (for relations-oriented diversity) and 73 (for task-oriented diversity) file-drawer null effects would need to be reported before those two relationships would lose statistical support. We also conducted additional analyses for each diversity attribute and found that functional background diversity was most positively related to performance $(r=.13, k=20,95 \% \mathrm{CI}=.09$ to .17$)$ and that age diversity showed the most negative perfor-

\footnotetext{
${ }^{4}$ We undertook additional OLS regressions whereby we regressed the effect of diversity-performance on the key independent variables. Results indicated that the pattern of findings for OLS regressions mirrors the pattern of findings reported here. We also undertook a stepwise regression procedure and found that adding each contextual variable was associated with significant incremental variance in the diversity-performance effect. Collectively, in these analyses, contextual variables accounted for 56 percent of the variance in relations-oriented effect sizes across studies. Further, the variance inflation factors in all cases were well below 10, which is the rule-of-thumb cutoff for high multicollinearity. The full results are available from the authors upon request. We thank our action editor, Jason Colquitt, for this suggestion.
} 
TABLE 2

Main Effects: The Relationship between Team Diversity and Performance ${ }^{\mathrm{a}}$

\begin{tabular}{|c|c|c|c|c|c|c|}
\hline Diversity Type & $\begin{array}{c}\text { Effect Sizes } \\
(k)\end{array}$ & $\begin{array}{l}\text { Total Teams } \\
\qquad(N)\end{array}$ & $\begin{array}{c}\text { Weighted } \\
\text { Mean } r\end{array}$ & $\begin{array}{c}95 \% \\
\text { Confidence } \\
\text { Interval }\end{array}$ & $\begin{array}{c}\text { Failsafe } \\
k\end{array}$ & $Q$ \\
\hline Relations-oriented diversity & 69 & 19,779 & -.03 & $-.05,-.02$ & 118 & $479.54 * *$ \\
\hline Gender & 26 & 5,473 & -.02 & $-.04, \quad .01$ & & \\
\hline Race/ethnicity & 22 & 7,089 & -.01 & $-.04, \quad .01$ & & \\
\hline Function & 20 & 3,085 & .13 & $.09, \quad .17$ & 65 & \\
\hline Education & 9 & 2,863 & -.02 & $-.06, \quad .01$ & & \\
\hline Tenure & 19 & 3,881 & .03 & $-.01, \quad .06$ & & \\
\hline
\end{tabular}

${ }^{\text {a }} N$ is the total number of teams counted by effect sizes; failsafe $k$ indicates the number of unpublished studies reporting null results needed to reduce the cumulative effect across studies to the point of nonsignificance $(p \geq .05)$ and is only reported for statistically significant results $(p<.05) ; Q$ is the effect size heterogeneity statistic indicating the possibility of moderators.

${ }^{* *} p<.01$

mance effect $(r=-.06, k=21,95 \%$ CI $=-.09$ to $-.04)$.

Table 2 also shows that considerable heterogeneity among effect sizes exists, as indicated by the $Q$-statistic. Both $Q$ values for relations- and taskoriented diversity are highly significant ( $p$ 's $<.01$ ), indicating that correlations vary across studies and that potential moderators might exist that can explain these correlations.

\section{Occupational Demography}

Hypotheses 1a and $1 \mathrm{~b}$ predicted that the negative effects of gender and race/ethnicity diversity would be weaker in more gender-balanced and ethnically balanced settings, respectively. We conducted categorical moderator analyses and contrasted the difference between majority male or majority white occupations and relatively gender-balanced and ethnically balanced occupations. Table 3 summarizes the results. The categorical model testing the moderating effect of occupational percent female was highly significant $\left(Q_{\mathrm{B}}[1]=39.19, p<.01\right)$. As hypothesized, gender diversity had a significant, negative effect on team performance in majority male occupational settings $(r=-.09, k=12,95 \%$ $\mathrm{CI}=-.12$ to -.05$)$. The effect of gender diversity was significantly positive in relatively gender balanced settings ( $r=.11, k=7,95 \% \mathrm{CI}=.06$ to .15$)$. The moderating effect of occupational percent minority was also significant $\left(Q_{\mathrm{B}}[1]=48.65, p<\right.$ .01). The average correlation was significantly negative in majority white occupations $(r=-.07$, $k=10,95 \%$ CI $=-.10$ to -.04$)$ and positive in relatively balanced occupations $(r=.11, k=6$, $95 \%$ CI $=.07$ to .14$)$. In addition, because the occupational gender and race/ethnicity demogra- phy variables were measured as continuous variables (i.e., occupational percent female and occupational percent minority), to further understand the patterns of these moderating effects, we also performed WLS regressions. In support of both hypotheses, we found that occupational percent female and minority accounted for significant amounts of variance in the correlations between gender and race/ethnicity diversity and team performance $\left(\beta=.32, p<.01, R^{2}=.10\right.$, for gender diversity; $\beta=.37, p<.01, R^{2}=.14$, for race/ ethnicity diversity). Significant values of $Q_{\mathrm{R}}$ for gender diversity $\left(Q_{\mathrm{R}}[1]=16.78, p<.01\right)$ and race/ethnicity diversity $\left(Q_{\mathrm{R}}[1]=22.71, p<.01\right)$ also indicate that both regression models were statistically significant.

Hypothesis 1c predicted that the negative effects of age diversity would be strengthened in occupations composed of relatively younger workers and weakened in relatively age-balanced occupations. We conducted a categorical analysis and did not find a strong moderating relationship $\left(Q_{\mathrm{B}}[1]=\right.$ $0.85, p>.10$ ) (see Table 3). Although occupations composed of younger workers displayed slightly more negative effects than occupations that were more balanced in terms of age, considering the nonsignificant $Q_{\mathrm{B}}$ and significantly overlapping confidence intervals, the two occupational groups were not statistically different.

Hypothesis $1 \mathrm{~d}$ proposed that the positive performance outcome of task-oriented diversity would be stronger in more balanced occupational settings. Contrary to this proposition, task-oriented diversity showed more positive performance effects in majority male and white settings. However, considering the nonsignificant subgroup results for balanced occupational settings across all 
TABLE 3

Contextual Influences: Occupational Demography ${ }^{\text {a, b }}$

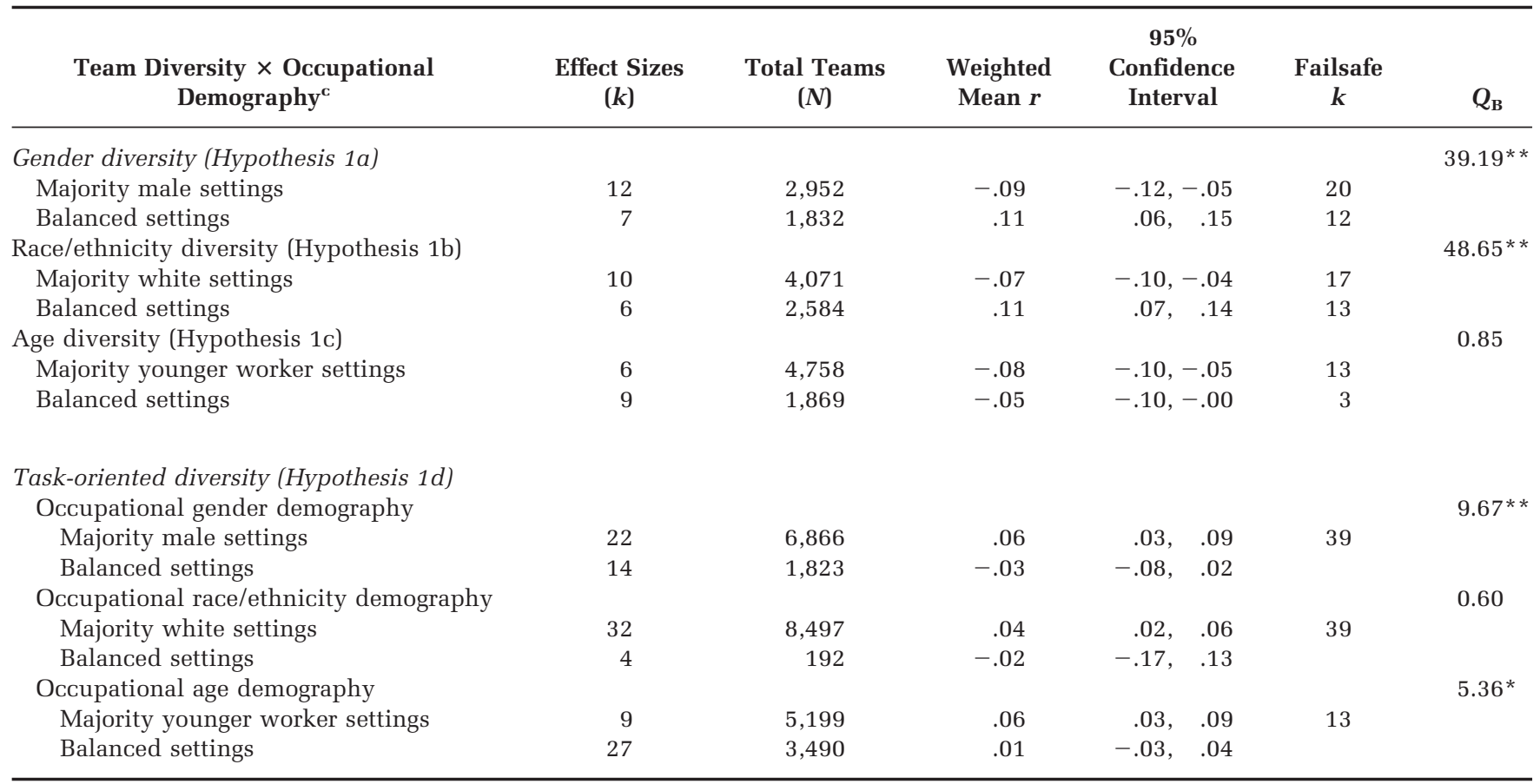

${ }^{a} N$ is the total number of teams counted by effect sizes; failsafe $k$ indicates the number of unpublished studies reporting null results needed to reduce the cumulative effect across studies to the point of nonsignificance $(p \geq .05)$ and is only reported for statistically significant results $(p<.05) ; Q_{\mathrm{B}}$ is the between-group heterogeneity statistic indicating the statistical significance of the categorical moderator model.

${ }^{\mathrm{b}}$ For continuous occupational demography variables (i.e., occupational percent female and occupational percent minority), we also conducted the WLS regression analyses and obtained the same pattern of findings as reported in this table of results (in relation to Hypothesis $1 \mathrm{a}$ and $1 \mathrm{~b})$.

${ }^{\mathrm{c}}$ Occupational settings in which the percent female or minority was below the overall mean level (i.e., 46.3 percent for female composition and 29 percent for minority composition) were considered as majority male or majority whites, respectively, in the analyses; we considered an occupation as a majority-younger-workers setting if the proportion of older workers (over 55 years old) in that occupation was less than the overall average (i.e., 18\%).

${ }^{*} p<.05$

$* * p<.01$

diversity attributes and the overlapping confidence intervals in general, we were unable interpret this finding meaningfully.

\section{Industry Setting}

Hypotheses 2a and 2b proposed that industry setting moderated the relationship between team diversity and performance outcomes. Table 4 presents the results. With regard to relations-oriented diversity, the overall categorical model testing industry impact was highly significant $\left(Q_{\mathrm{B}}[2]=\right.$ 209.89, $p<.01$ ). As predicted in Hypothesis 2a, relations-oriented diversity had a positive effect on performance in service industries $(r=.07, k=21$, $95 \%$ CI $=.05$ to .09). Inconsistently with Hypothesis 2a, however, in the manufacturing industry setting, the effect of relations-oriented diversity was negative $(r=-.04, k=16,95 \% \mathrm{CI}=-.07$ to
-.01) and interestingly, relations-oriented diversity displayed the strongest negative performance effect in high-technology industry settings $(r=$ $-.18, k=21,95 \% \mathrm{CI}=-.20$ to -.15$)$. This finding is also resistant to unpublished null effects with a failsafe $k$ of 152 .

Regarding Hypothesis 2b, we found weak support for the moderating effects of industry setting on the performance outcome of task-oriented diversity. The overall categorical model was modestly significant $\left(Q_{\mathrm{B}}[2]=7.28, p<.05\right)$. Task-oriented diversity was positively related to performance in the high-technology industry setting, as hypothesized ( $r=.06, k=23,95 \% \mathrm{CI}=.04$ to .09 ), but this effect was only slightly larger than the overall main effect of task-oriented diversity $(r=.04)$. We did not find any significant support for industry moderating effects on task-oriented diversity effects in the manufacturing and service settings. 
TABLE 4

Contextual Influences: Industry Setting ${ }^{a}$

\begin{tabular}{|c|c|c|c|c|c|c|}
\hline Team Diversity $\times$ Industry Setting ${ }^{b}$ & $\begin{array}{c}\text { Effect Sizes } \\
(k)\end{array}$ & $\begin{array}{c}\text { Total Teams } \\
\qquad(N)\end{array}$ & $\begin{array}{l}\text { Weighted } \\
\text { Mean } r\end{array}$ & $\begin{array}{c}95 \% \\
\text { Confidence } \\
\text { Interval }\end{array}$ & $\begin{array}{c}\text { Failsafe } \\
k\end{array}$ & $Q_{\mathrm{B}}$ \\
\hline High-technology industry & 21 & 6,068 & -.18 & $-.20,-.15$ & 152 & \\
\hline Service industry & 21 & 9,139 & .07 & $.05, \quad .09$ & 58 & \\
\hline Manufacturing industry & 16 & 3,687 & -.04 & $-.07,-.01$ & 8 & \\
\hline Task-oriented diversity (Hypothesis 2b) & & & & & & $7.28^{*}$ \\
\hline High-technology industry & 23 & 6,475 & .06 & $.04, \quad .09$ & 45 & \\
\hline Service industry & 16 & 1,702 & -.00 & $-.05, \quad .05$ & & \\
\hline Manufacturing industry & 3 & 1,194 & .01 & $-.05, \quad .06$ & & \\
\hline
\end{tabular}

${ }^{\text {a }} \mathrm{N}$ is the total number of teams counted by effect sizes; failsafe $k$ indicates the number of unpublished studies reporting null results needed to reduce the cumulative effect across studies to the point of nonsignificance $(p \geq .05)$ and is only reported for statistically significant results $(p<.05) ; Q_{\mathrm{B}}$ is the between-group heterogeneity statistic indicating the statistical significance of the categorical moderator model.

b Three industry categories were analyzed: (1) high-technology included electronics/semiconductors, information processing, telecommunication, and professional R\&D service; (2) service included retail trade, finance/insurance, health care, education service, moving/ transportation, and government service; (3) manufacturing industries included automobile manufacturing, paper and wood manufacturing, textile manufacturing, oil and gas extraction, and general and chemical product manufacturing.

$* p<.05$

$* * p<.01$

\section{Team Interdependence and Team Type}

Table 5 presents the results regarding the effects of team-level moderators on the relationship between team diversity and performance. Hypothesis 3 proposed that effects of task-oriented diversity will be stronger and the effects of relations-oriented diversity will be weaker among highly interdependent teams. The findings with regard to relationsoriented diversity were contrary to this hypothesis. Although the categorical model for relations-oriented diversity was significant $\left(Q_{\mathrm{B}}[2]=174.21\right.$, $p<.01$ ), among teams with low interdependence relations-oriented diversity was positively related to performance $(r=.08)$, and among teams with moderate and high interdependence, relations-oriented diversity was negatively related to performance ( $r=-.12$ and $r=-.04$, respectively). The categorical analysis for task-oriented diversity supported the hypothesized pattern, although the overall moderating model only showed limited statistical support $\left(Q_{\mathrm{B}}[2]=7.14, p<.05\right)$. The positive performance effect of task-oriented diversity increased as team tasks, goals, and outcomes became more interdependent; however, these results also need to be interpreted cautiously because the 95 percent confidence interval of the low-interdependence subgroup included zero and overlapped with those for the other two subgroups.

Our final hypothesis addressed whether team type-the length of time a team was expected to exist (i.e., long-term versus short-term)—affected the relationship between team diversity and performance. Hypothesis 4 proposed that the negative effects of relations-oriented diversity would be strengthened in long-term teams. We found strong support for relations-oriented diversity: the categorical moderator model was highly significant $\left(Q_{\mathrm{B}}[1]=222.91, p<.01\right)$. The performance effect of relations-oriented diversity was positive in relatively short-term teams $(r=.09, k=23,95 \% \mathrm{CI}=$ .07 to .12) but became negative in more stable or long-term teams $(r=-.14 ; k=43,95 \% \mathrm{CI}=-.16$ to -.12 ). Both findings are resistant to unpublished null effects, with failsafe $k$ 's of 89 and 305, respectively. For task-oriented diversity, we did not find a statistical support for the hypothesis $\left(Q_{\mathrm{B}}[1]=0.63\right.$, $p>.10$ ). Although the performance effect of taskoriented diversity was more positive in short-term teams $(r=.08)$ than in long-term teams $(r=.04)$, these subgroup results were not statistically different from each other.

\section{DISCUSSION}

This meta-analytic review took stock of past research on the diversity-performance relationship conducted in organizational settings over the past 15 years and examined the sensitivity of this relationship to contextual variables at multiple levels. Our findings revealed that when one considers the relationship between all types of diversity (i.e., collapsing relations- and task-oriented distinction) 
TABLE 5

Contextual Influences: Team Interdependence and Team Type ${ }^{\mathrm{a}}$

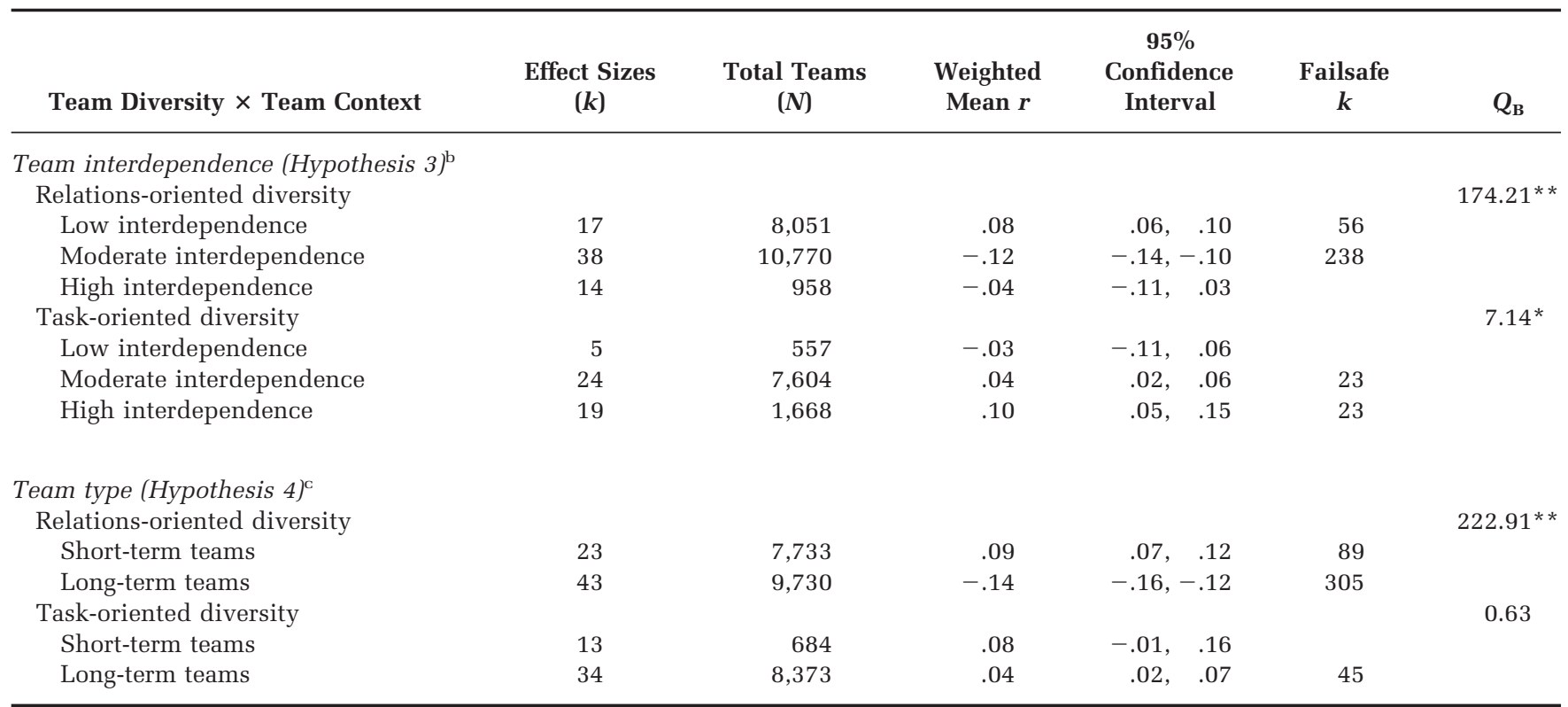

${ }^{a} N$ is the total number of teams counted by effect sizes; failsafe $k$ indicates the number of unpublished studies reporting null results needed to reduce the cumulative effect across studies to the point of nonsignificance $(p \geq .05)$ and is only reported for statistically significant results $(p<.05) ; Q_{\mathrm{B}}$ is the between-group heterogeneity statistic indicating the statistical significance of the categorical moderator model.

${ }^{\mathrm{b}}$ Low-interdependence teams included, for example, production or sales teams with sequentially related activities and/or individualbased goals or rewards; high-interdependence teams included, for example, cross-functional R\&D teams that frequently exchanged ideas and shared common goals.

${ }^{\mathrm{c}}$ Short-term teams involved, for example, project-based teams existing for a limited period of time; permanent work teams or general work teams existing for longer than two years were generally considered relatively long-term teams.

${ }^{*} p<.05$

** $p<.01$

and performance, the direct effect of diversity on performance is essentially zero. Relations-oriented diversity attributes such as gender, race/ethnicity, and age had very small, though significantly negative, effects on team performance. Although functional diversity had a more substantial positive effect, other forms of task-oriented diversity (i.e., education and tenure) also had very small effects on team performance. These findings make it appear that diversity does not really matter for team performance. However, we contend that these weak direct relationships may be obscuring the specific conditions under which diversity can have beneficial or detrimental effects on performance outcomes. Our study developed and tested a framework identifying boundary conditions under which the diversity-performance relationship is likely to be significant. Specifically, we found that after we accounted for moderating variables at multiple levels, diversity effects doubled or tripled in size. Further, industry and occupational moderators, which have received relatively scant attention in past research, explained significant variance in relationsoriented diversity effects across studies. Below we discuss the theoretical, empirical, and practical implications of our findings.

\section{The Role of Occupational Demography and Industry Setting as Context}

We found that in occupations dominated by male or by white employees, gender and ethnic diversity had more negative effects on performance outcomes. These findings draw attention to the importance of extraorganizational context in shaping diversity outcomes, and we call for a more detailed and comprehensive acknowledgement of macrolevel context in future research. Apart from stereotypes associated with underrepresented groups in a particular occupational context, implicit status differences between demographic groups may also be a mechanism by which contextual factors such as occupational demography filter into team-level interactions (see Ridgeway, 1991, 1997). The dominance of a particular demographic group within a particular occupational setting can signal greater access to resources and privilege for this group. The privilege accrued by a demographic group in a par- 
ticular context may provide team members belonging to this group with an "expertise advantage"; these group members may be considered more competent, and the contributions of the members of low-status demographic groups may be devalued in these settings (Berger, Ridgeway, Fisek, \& Norman, 1998; Berger, Ridgeway, \& Zelditch, 2002). Indeed, a rich body of sociopsychological research has shown that, in small groups, interpersonal interactions tend to replicate larger societal status differentials (Berger et al., 1998, 2002) and may account for the suboptimal performance outcomes of gender-diverse and ethnically diverse teams in majority male and white settings.

We propose that a closer examination of the occupational context in which teams are embedded can provide researchers with an understanding of broader structural inequality and its implications for team-level diversity outcomes. Further, although we were not able to test the role of organizational practices in these settings, research suggests that these status differentials are further legitimized by organizational practices that favor some demographic groups over others (Ridgeway, 1991, 1997). Thus, another direction for future research could be to examine the role that organizational practices play in either enhancing or mitigating status-based processes in a specific occupational context.

Although statistically inconclusive, our finding was that task-oriented diversity had weakly positive effects in male/white dominated settings. This pattern is contrary to our theoretical arguments. Although we caution against overinterpreting this finding, we acknowledge that in these more homogeneous settings, categorization based on demographic characteristics may not have been sufficient to mitigate the elaborative potential of taskoriented diversity. We call for more research on possible mechanisms mediating task-oriented diversity effects in these occupational settings.

Our findings indicated that the industry settings in which teams were embedded also had interesting implications for team-level diversity-based outcomes. We found that relations-oriented diversity had positive effects in service industry settings and slightly negative effects in manufacturing settings. In addition to the market competence perspective (Richard et al., 2007) discussed in developing our hypotheses, some additional considerations should also perhaps be taken into account. Service settings (for example, retail establishments and restaurants) involve front-line customer contact, and the costs of interactions based on negative categorizations are high in this context. Hence, firms embedded in these industries may engage in proactive diversity management efforts to address gender-, ethnicity-, and age-based issues in the workplace. ${ }^{5}$ Specific forms of training intended at changing behaviors targeted at demographically dissimilar employees and customers may be implemented in these settings. In contrast, in manufacturing settings, where we found negative effects, firms do not face similar pressures and may be less likely to directly address these aspects of team diversity.

Surprisingly, we found that in high-technology settings, relations-oriented diversity had a more substantial negative effect. Recently, DiTomaso and colleagues found that, in 24 firms that fit our definition of high-technology settings, white men received more training, mentoring, and coaching and also the most favorable performance evaluations, relative to any other demographic group (DiTomaso, Post, Smith, Farris, \& Cordero, 2007). These characteristics of high-technology firms may enhance ethnicity- and gender-based status differentials. It would appear that white men occupy a high-status position (reflected in these favorable employment outcomes) in the high-technology sector (DiTomaso, Post, Smith et al., 2007) and would enjoy an "expertise advantage" relative to women or minorities. Therefore, the status-based processes that we discussed earlier could also account for the negative effects of relations-oriented diversity in this industry. Furthermore, like manufacturing firms, high-technology firms may not face pressures to proactively adopt diversity management practices. These findings call for a finer-grained understanding of the industry context framing diversity-based outcomes. For example, future research could apply contingency-based perspectives and examine whether a fit between firms' diversity management strategies and industry-level contingencies explains the outcomes of diversity at the team level. Longitudinal studies that examine how specific industry trends influence firms' responses to diversity and their implications for team performance could be an avenue for future inquiry.

We conclude this section by noting that our findings challenge the assumption, born from socialcategorization theory, that some aspects of diversity necessarily have detrimental effects on team performance. Although relations-oriented diversity attributes have been typically associated with categorization-based processes (Jackson et al., 1995;

\footnotetext{
${ }^{5}$ Consider as an example the negative publicity received by Denny's Restaurants as a result of discrimination charges and their subsequent efforts to train and reward appropriate behaviors toward demographically dissimilar employees and customers.
} 
Jehn et al., 1999), we found that the effects of these attributes on team performance ranged from significantly negative (in the high-technology industry and in male/white dominated occupations) to significantly positive (in the service industry and in gender-/ethnicity-balanced occupations). The effects of task-oriented diversity, however, were invariant across these contexts. Current applications of social identity theory or social categorization theory in diversity research are insufficient for explaining these findings. These theoretical frameworks were originally developed to explain the outcomes of differences in minimal group settings and may not capture the effects of demographic attributes among naturally occurring work groups in these contexts (see also DiTomaso, Post, Smith, Farris, \& Cordero, 2007; Linnehan \& Konrad, 1999). Therefore, these findings suggest that a priority for future research is to investigate how the demography of a work context and the characteristics of the industry settings in which teams are embedded can influence the performance outcomes of gender or ethnic diversity. We call for more context-focused diversity research, which would entail targeting particular settings in which either the negative or the positive consequences of team diversity are more likely. Such efforts could facilitate the development of new theoretical approaches that incorporate the status-based or strategic management perspectives we outlined above.

\section{Team-Level Contextual Influences}

Our review of past literature suggested that there has been a growing emphasis on the role of moderators in diversity research and that, predominantly, past research has focused on team-level moderators such as team tenure, task interdependence, and task complexity (see Van Knippenberg \& Schippers [2007] for a review). In view of this research, we proposed that contextual factors such as team interdependence and team type would moderate the effects of diversity on performance in such a way that elaboration-based processes would be more likely to be observed in more interdependent or shorter-lived teams (Bowers et al., 2000; Jehn et al., 1999). Contrary to our predictions, we found that relations-oriented diversity had the most negative effects in moderately interdependent teams. These findings suggest that the interactive effects of team diversity and interdependence may be more complex than acknowledged in the past. Moderately interdependent tasks may impose constraints that interfere with the elaborative potential of diversity attributes but are not so demanding that team members must overcome categorization-based processes and collaborate with each other. Although the effect sizes were smaller, a lower level of interdependence was associated with positive performance outcomes for relations-oriented diversity. In teams with low interdependence, the distinct nature of each individual team member's task and a lower need to exchange information may create a situation in which team members are not frustrated with dissimilar group members and are able to recognize the contributions of other members to the team goals (Pelled et al., 1999).

In support of our propositions, findings indicated that in short-term teams (such as temporary project teams), relations-oriented diversity had a positive effect on performance. In these teams, the expectation of a finite amount of time to complete tasks may force group members to exploit the full elaborative potential of diversity attributes. In longterm teams, team members may feel less compelled to identify and utilize diverse perspectives and may also have more opportunity to bring up conflicts that may be detrimental to group functioning. We note that we had limited ability to test temporal influences on diversity effects more directly in this meta-analysis. Measures of team tenure or longevity may yield a different pattern of findings (Harrison et al., 2001; Schippers et al., 2003).

Overall, it is interesting to note that these teamlevel moderators, which have received the most attention in past research, had weaker moderating effects on diversity outcomes than industry and occupational variables. Moreover, these variables had a more significant moderating effect on relations-oriented diversity effects than on task-oriented diversity effects. In general, we found that moderately interdependent teams and long-term teams could face challenges with increasing diversity; less interdependent teams and short-term teams would benefit from greater demographic diversity among team members. These findings suggest that more research on the psychological processes underlying these moderating effects is needed in these specific team contexts. For example, understanding whether role stress or role overload associated with greater team interdependence has implications for the manner in which team members deal with demographic differences would be useful. These team-level moderators may also need to be considered in conjunction with other macro-level contextual variables. For example, it would be interesting to understand whether taskrelated contingencies are more likely to induce conflict in demographically diverse groups when the macrolevel context enhances categorizationbased processes. 


\section{Caveats, Limitations, and Future Directions}

The meta-analytic approach we applied in this study has some limitations. One concern may be that the sample is small and may be associated with second-order sampling error, which is particularly relevant for moderator analysis (Hunter \& Schmidt, 1990). However, the failsafe $k$ 's we report are fairly large and suggest that, even at the rate at which diversity research is being conducted, at least a decade more of research may be required to overturn the significant findings reported here.

We note that we were also limited in our ability to code contextual variables, as the studies' descriptions of research settings and team tasks were often scanty. For example, despite the increasing attention to temporal effects on team diversity outcomes, the lack of information regarding team tenure or team duration was especially troubling. We propose that future studies provide more detailed descriptions of research settings and acknowledge the role that these factors play in explaining research findings. Because of theoretical considerations and data availability, we considered only a subset of the possible moderating influences on team diversity outcomes. Missing from this analysis is the role that organizational context and other extraorganizational factors can play in shaping diversity outcomes. Aspects of organizational context such as managerial demography, climate, culture, and leadership also merit closer scrutiny in future research. Other extraorganizational factors, such as societal and political events (e.g., immigration trends, passage of key legislation), may also be important to consider in the future but were outside the scope of this study. Further, we note that for testing the effects of occupational demography, we could only include U.S.-based samples. These findings may vary in other cultural contexts.

Finally, we used a simplified relations-oriented versus task-oriented typology while considering contextual effects on diversity outcomes; this dichotomy corresponded to the categorizationversus elaboration-based processes underlying diversity effects. Other typologies, such as surfaceversus deep-level diversity, may also be pertinent to this analysis and should be considered in the future. Contextual effects on the outcomes of deeplevel diversity variables, such as personality, cognitive ability, values, and attitudes, were also outside the scope of the present study and may be of interest in future research. We were also unable to incorporate the faultlines approach that has been a growing focus in diversity research. Of the studies we initially reviewed, 5 percent applied a faultlines-based operationalization of diversity. We also note that, although conceptually interesting, field research directly applying faultlines-based measures is not abundant and has yielded inconsistent results (e.g., Gibson \& Vermeulen, 2003; Greer \& Jehn, 2008; Lau \& Murnighan, 2005; Li \& Hambrick, 2005). We propose that future research also examine how contextual moderators may enhance the strength and number of faultlines in teams to resolve these mixed findings.

Harrison and Klein (2007) offered several guidelines for the measurement of diversity in terms of three dimensions: separation, variety, and disparity. These authors proposed that the measurement of various diversity attributes should be based on the specific dimension of diversity considered. In this meta-analytic review, because we relied on measurement of diversity that predated this 2007 article, we were unable to adopt these guidelines. However, complementing Harrison and Klein's (2007) arguments, we note that the malleability of relations-oriented diversity to occupational, industry, and team-level contextual variables underscores the importance of clarifying the specific dimension associated with these demographic attributes in the future. A comprehensive contextual analysis may also help researchers determine whether a specific demographic attribute is likely to manifest as "separation," "variety," or "disparity" in teams. For example, diversity could be conceptualized as variety in short-term teams, in service settings, and in demographically balanced settings but as disparity in long-term teams, in male/white dominated occupations, and in hightechnology settings.

\section{Implications for Diversity Management}

A context-based approach to workplace diversity research can potentially provide practical insights that might enhance the effectiveness of diversity management practices. In some work contexts, it is important to recognize that diversity at the work group level may be problematic. In these settings, diversity interventions aimed directly at targeting behaviors driven by stereotyping and bias against underrepresented groups and ensuring representation at higher levels may be necessary to reverse negative diversity-based outcomes. Furthermore, organizations can directly address the dominance of a demographic majority in a particular labor market by proactively implementing partnerships with educational institutions to increase gender- and racebased diversity in the applicant pool. These observations may be particularly important in the case of the high-technology settings included in our analysis. At a time when this sector of the economy is 
growing rapidly, there is also growing concern among policy makers regarding the declining ratio of women and minorities in this industry (Information Technology Association of America, 2003). The negative performance effects of diversity that we found in high technology may also reflect an "unfriendly" atmosphere for women and minorities in this setting. Partnerships with high schools and college campuses to increase gender and ethnic diversity in mathematics, science, and engineering could enhance the diversity of the applicant pool and provide a more balanced representation of various demographic groups in firms, thereby mitigating the problematic consequences of demographic diversity at the work group level. We note that a few prominent firms in this industry are already making these proactive efforts, and our findings underscore the value of these initiatives.

With respect to our findings regarding the effects of team-level moderators, we propose that diversity management practices need to specifically address the level of interdependence or longevity that team members will encounter. Teams performing more interdependent tasks over the long term may need ongoing training interventions or team coaching that facilitates group decision making and conflict resolution. A more tailored team-focused approach to designing diversity management practices may enhance the relevance and effectiveness of these practices in teams. In general, a "contextual diagnosis" will allow firms to develop diversity management practices that are tailored to reduce categorization-based processes and enhance elaboration-based processes at the team level. Overall, long-term teams that perform interdependent tasks in less demographically balanced occupational settings may be the most vulnerable to categorization-based processes and may need more direct and focused interventions than other types of teams.

\section{Conclusion}

Past reviews have labeled differing theoretical perspectives and contradictory findings in diversity research as the "double-edged sword of diversity" (e.g., Webber \& Donahue, 2001). In this article, we propose a new agenda for diversity researchone that moves beyond a debate regarding the potential benefits or costs of diversity and highlights the inherent context dependence of diversity effects in organizations. We note that inadequately reporting and acknowledging context not only obscures the important consequences of diversity in organizations, but also hampers efforts to synthesize and integrate the cumulative evidence from the past; handicaps future theory building; and limits researchers' ability to distill the practical implications of findings. This study presents a roadmap for context-focused research that we hope encourages researchers to more carefully account for context in future studies, facilitates greater theoretical integration of the macro and micro levels of analysis, and paves the way for new theoretical and methodological developments.

\section{REFERENCES}

*Ainoya, N. 2004. Demographic diversity, team process, and team performance: Assessing moderator effects of cognitive conflict management practices and task interdependence. Unpublished doctoral dissertation, University of Southern California.

Allison, P. D. 1978. Measures of inequality. American Sociological Review, 43: 865-880.

Allport, G. 1954. The nature of prejudice. Cambridge, MA: Addison-Wesley.

*Ancona, D. G., \& Caldwell, D. F. 1992. Demography and design: Predictors of new product team performance. Organization Science, 3: 321-341.

*Balkundi, P., Kilduff, M., Barsness, Z. L., \& Michael, J. D. 2007. Demographic antecedents and performance consequences of structural holes in work teams. Journal of Organizational Behavior, 28: 241-260.

Bamberger, P. 2008. Beyond contextualization: Using context theories to narrow the micro-macro gap in management research. Academy of Management Journal, 51: 839-846.

Batt, R. 2002. Managing customer service: Human resource practices, quit rates, and sales growth. Academy of Management Journal, 45: 587-597.

*Baugh, S. G., \& Graen, G. B. 1997. Effects of team gender and racial composition on perceptions of team performance in cross-functional teams. Group and Organization Management, 22: 366-383.

Berger, J., Fisek, M. H., Norman, R. Z., \& Zelditch, M. 1977. Status characteristics in social interactions: An expectations states approach. New York: Elsevier.

Berger, J., Ridgeway, C., Fisek, M. H., \& Norman, R. Z. 1998. The legitimation and delegitimation of power and prestige orders. American Sociological Review, 63: $379-405$.

Berger, J., Ridgeway, C., \& Zelditch, M. 2002. The construction of status and referential structures. Sociological Theory, 20: 157-179.

Blau, P. M. 1977. Inequality and heterogeneity: A primitive theory of social structure. New York: Free Press.

Bourgeois, L. J. 1985. Strategic goals, perceived uncer- 
tainty, and economic performance in volatile environments. Academy of Management Journal, 28: $548-573$.

Bowers, C. A., Pharmer, J. A., \& Salas, E. 2000. When member homogeneity is needed in work teams: A meta-analysis. Small Group Research, 31: 305-327.

Brewer, M. B. 1988. A dual process model of impression formation. In T. K. Srull \& R. S. Wyer (Eds.), Advances in social cognition, vol. 1: 1-36. Hillsdale, NJ: Erlbaum.

*Bunderson, J. S. 2003. Recognizing and utilizing expertise in work groups: A status characteristics perspective. Administrative Science Quarterly, 48: 557591.

Burns, T., \& Stalker, G. M. 1961. The management of innovation. London: Tavistock.

*Cady, S. H., \& Valentine, J. 1999. Team innovation and perceptions of consideration: What difference does diversity make? Small Group Research, 30: 730750.

*Campion, M. A., Medsker, G. J., \& Higgs, A. C. 1993. Relations between work group characteristics and effectiveness: Implications for designing effective work groups. Personnel Psychology, 46: 823-850.

*Campion, M. A., Papper, E. M., \& Medsker, G. J. 1996. Relations between work team characteristics and effectiveness: A replication and extension. Personnel Psychology, 49: 429-452.

Cappelli, P., \& Sherer, P. 1991. The missing role of context in OB: The need for a meso-level approach. In L. L. Cummings \& B. M. Staw (Eds.), Research in organizational behavior, vol.13: 55-110. Greenwich, CT: JAI Press.

Carpenter, M. A., Geletkanycz, M. A., \& Sanders, W. G. 2004. Upper echelons research revisited: Antecedents, elements, and consequences of top management team composition. Journal of Management, 30: 749-778.

Chatman, J. A., \& Flynn, F. 2001. The influence of demographic heterogeneity on the emergence and consequences of cooperative norms in work teams. Academy of Management Journal, 44: 956-974.

${ }^{*}$ Choi, J. N. 2007. Group composition and employee creative behavior in a Korean electronics company: Distinct effects of relational demography and group diversity. Journal of Occupational and Organizational Psychology, 80: 213-234.

Choi, J. N., Price, R. H., \& Vinokur, A. D. 2003. Self-efficacy changes in groups: Effects of diversity, leadership, and group climate. Journal of Organizational Behavior, 24: 357-372.

Cleveland, J. N., Festa, R. M., \& Montgomery, L. 1988. Applicant pool composition and job perceptions: Impact on decisions regarding an older applicant. Journal of Vocational Behavior, 32: 112-125.

Cleveland, J. N., Montgomery, L., \& Festa, R. M. 1984.
Group composition and job perceptions: Impact on decision about sustainability of applicants for group membership. Unpublished manuscript, Baruch College, City University of New York.

Collins, C. J., \& Smith, K. G. 2006. Knowledge exchange and combination: The role of human resource practices in the performance of high-technology firms. Academy of Management Journal, 49: 544-560.

*Colquitt, J. A., Noe, R. A., \& Jackson, C. L. 2002. Justice in teams: Antecedents and consequences of procedural justice climate. Personnel Psychology, 55: 83109.

Combs, J., Liu, Y., Hall, A., \& Ketchen, D. 2006. How much do high-performance work practices matter? A meta-analysis of their effects on organizational performance. Personnel Psychology, 59: 501-528.

Datta, D. K., Guthrie, J. P., \& Wright, P. M. 2005. Human resource management and labor productivity: Does industry matter? Academy of Management Journal, 48: 135-145.

De Dreu, C. K. W., \& Weingart, L. R. 2003. Task versus relationship conflict, team performance, and team member satisfaction: A meta-analysis. Journal of Applied Psychology, 88: 741-749.

Devine, D. J., \& Phillips, J. L. 2001. Do smarter teams do better? A meta-analysis of cognitive ability and team performance. Small Group Research, 32: 507-532.

DiTomaso, N., Post, C., \& Parks-Yancy, R. 2007. Workforce diversity and inequality: Power, status, and numbers. Annual Review of Sociology, 33: 473501.

DiTomaso, N., Post, C., Smith, D. R., Farris, G. F., \& Cordero, R. 2007. Effects of structural position on allocation and evaluation decisions for scientists and engineers in industrial R\&D. Administrative Science Quarterly, 52: 175-207.

*Drach-Zahavy, A., \& Somech, A. 2002. Team heterogeneity and its relationship with team support and team effectiveness. Journal of Educational Administration, 40: 44-66.

Drazin, R., \& Van de Ven, A. 1985. Alternative forms of fit in contingency theory. Administrative Science Quarterly, 30: 514-539.

Dubin, R. 1976. Theory building in applied areas. In M. D. Dunnette (Ed.), Handbook of industrial and organizational psychology: 17-39. Chicago: Rand McNally.

Eagly, A. H. 1995. The science and politics of comparing women and men. American Psychologist, 50: 145158.

Eagly, A. H., \& Steffen, V. J. 1984. Gender stereotypes stem from the distribution of women and men into social roles. Journal of Personality and Social Psychology, 46: 735-754.

Ely, R. J. 1994. The effects of organizational demographics and social identity on relationships among pro- 
fessional women. Administrative Science Quarterly, 39: 203-238.

Ely, R. J. 1995. The power in demography: Women's social constructions of gender identity at work. Academy of Management Journal, 38: 589-634.

*Ely, R. J. 2004. A field of group diversity, participation in diversity education programs, and performance. Journal of Organizational Behavior, 25: 755-780.

Fiske, S. T. 1993. Controlling other people: The impact of power on stereotyping. American Psychologist, 48: 621-628.

Fiske, S. T. 1998. Stereotyping, prejudice, and discrimination. In D. T. Gilbert, S. T. Fiske, \& G. Lindzey (Eds.), Handbook of social psychology: 357-411. Boston: McGraw-Hill.

Fiske, S. T., Cuddy, A. J. C., Glick, P., \& Xu, J. 2002. A model of (often mixed) stereotype content: Competence and warmth respectively follow from perceived status and competition. Journal of Personality and Social Psychology, 82: 878-902.

Frink, D. D., Robinson, R. K., Reithel, B., Arthur, M. M., Ferris, G. R., Kaplan, D. M. et al. 2003. Gender demography and organizational performance: A two study investigation with convergence. Group and Organization Management, 28: 127-147.

Gaertner, S. L., \& Dovidio, J. F. 2000. Reducing intergroup bias: The common intergroup identity model. Philadelphia: Psychology Press.

Gibson, C., \& Vermeulen, F. 2003. A healthy divide: Subgroups as a stimulus for team learning behavior. Administrative Science Quarterly, 48: 202-239.

Gomez-Mejia, L., \& Balkin, D. 1992. Determinants of faculty pay: An agency theory perspective. Academy of Management Journal, 35: 921-955.

Greer, L. L., \& Jehn, K. A. 2008. Where perception meets reality: The effects of different types of faultine perceptions, asymmetries, and realities on intersubgroup conflict and workgroup functioning. Working paper, Leiden University, The Netherlands.

Gully, S. M., Incalcaterra, K., Joshi, A., \& Beaubien, J. M. 2002. A meta-analysis of team efficacy, potency and performance: Interdependence and level of analysis as moderators of observed relationships. Journal of Applied Psychology, 87: 819-832.

Hackman, J. R. 1987. The design of work teams. In J. W. Lorsch (Ed.), Handbook of organizational behavior: 315-342. Englewood Cliffs, NJ: Prentice-Hall.

Haleblian, J., \& Finkelstein, S. 1993. Top management team size, CEO dominance, and firm performance: The moderating role of environmental turbulence and discretion. Academy of Management Journal, 36: $844-863$.

Hambrick, D. C., Cho, T. S., \& Chen, M. 1996. The influence of top management team heterogeneity on firms' competitive move. Administrative Science Quarterly, 41: 659-684.
Hambrick, D. C., \& Finkelstein, S. 1987. Managerial discretion: A bridge between polar views on organizations. In L. L. Cummings \& B. M. Staw (Eds.), Research in organizational behavior, vol. 9: 369-406. Greenwich, CT: JAI Press.

Hambrick, D. C., \& Mason, P. A. 1984. Upper echelons: The organization as a reflection of its top managers. Academy of Management Review, 9: 193-206.

Harrison, D. A., \& Klein, K. J. 2007. What's the difference? Diversity constructs as separation, variety, or disparity in organizations. Academy of Management Review, 32: 1199-1228.

Harrison, D. A., Price, K. H., \& Bell, M. P. 1998. Beyond relational demography: Time and the effects of surface- and deep-level diversity on work group cohesion. Academy of Management Journal, 41: 96107.

Harrison, D. A., Price, K. H., Gavin, J. H., \& Florey, A. T. 2002. Time, teams, and task performance: Changing effects of surface- and deep-level diversity on group functioning. Academy of Management Journal, 45: 1029-1045.

Hedge, L. V., \& Olkin, I. 1985. Statistical methods for meta-analysis. Orlando, FL: Academic Press.

${ }^{*}$ Herron, M. T. 1993. The effects of the ethnic and gender diversity of work team on the perceptions of performance outputs. Unpublished doctoral dissertation, California School of Professional Psychology, Los Angeles.

Hilton, J. J., \& von Hippel, W. 1996. Stereotypes. In J. T. Spence, J. M. Darley, \& D. J. Foss (Eds.), Annual review of psychology, vol. 47: 237-271. Palo Alto, CA: Annual Reviews.

Homan, A. C., \& Van Knippenberg, D. 2003. The beneficial effects of cross-categorizing informational and demographical diversity in groups. Paper presented at the 11th European Congress of Work and Organizational Psychology, Lisbon.

Horwitz, S. K., \& Horwitz, I. B. 2007. The effects of team diversity on team outcomes: A meta-analytic review of team demography. Journal of Management, 33: 967-1015.

Huffcutt, A. I., \& Arthur, W., Jr. 1995. Development of a new outlier statistic for meta-analytic data. Journal of Applied Psychology, 80: 327-334.

Hunter, J. E., \& Schmidt, F. L. 1990. Methods of metaanalysis: Correcting error and bias in research findings. Newbury Park, CA: Sage.

Hultin, M., \& Szulkin, R. 1999. Wages and unequal access to organizational power: An empirical test of gender discrimination. Administrative Science Quarterly, 44: 453-472.

Ilgen, D. R., Hollenbeck, J. R., Johnson, M., \& Jundt, D. 2005. Teams in organization: From input-processoutput models to IMOI models. In S. Fiske, D. L. Schacter, \& A. Kasdin (Eds.), Annual review of psy- 
chology, vol. 56: 517-543. Palo Alto, CA: Annual Reviews.

Information Technology Association of America. 2003. Report of the Information Technology Association of America (ITAA) blue ribbon panel on IT diversity. Presented at the National IT Workforce Convocation, Arlington, VA.

*Jackson, S. E., \& Joshi, A. 2004. Diversity in social context: A multi-attribute, multi-level analysis of team diversity and sales performance. Journal of Organizational Behavior, 25: 675-702.

Jackson, S. E., Joshi, A., \& Erhardt, N. L. 2003. Recent research on team and organizational diversity: SWOT analysis and implications. Journal of Management, 29: 801-830.

Jackson, S. E., May, K. E., \& Whitney, K. 1995. Under the dynamics of diversity in decision-making teams. In R. A. Guzzo \& E. Salas (Eds.), Team effectiveness and decision making in organizations: 204-261. San Francisco: Jossey-Bass.

* Jarrell, K. A. 2002. Job-related diversity and service team outcomes: New insights into the roles of task structure and process conflict. Unpublished doctoral dissertation, Syracuse University.

*Jehn, K. A., \& Bezrukova, K. 2004. A field study of group diversity, workgroup context, and performance. Journal of Organizational Behavior, 25: 703-729.

*Jehn, K. A., Northcraft, G. B., \& Neale, M. A. 1999.Why differences make a difference: A field study of diversity, conflict, and performance in workgroups. Administrative Science Quarterly, 44: 741-763.

Johns, G. 2006. The essential impact of context on organizational behavior. Academy of Management Review, 31: $386-408$.

*Joshi, A. 2002. How does context matter? Examining the process and performance outcomes of work team heterogeneity. Unpublished doctoral dissertation, Rutgers University, New Brunswick, NJ.

Joshi, A., Liao, H., \& Jackson, S. E. 2006. Cross-level effects of workplace diversity on sales performance and pay. Academy of Management Journal, 49: $459-481$.

Jost, J. T., \& Banaji, M. R. 1994. The role of stereotyping in system-justification and the production of false consciousness. British Journal of Social Psychology, 33: 1-27.

*Kearney, E., \& Gerbert, D. 2009. Managing diversity and enhancing team outcomes: The promise of transformational leadership. Journal of Applied Psychology: In press.

*Kearney, E., Gerbert, D., \& Voelpel, S. 2009. When and how diversity benefits teams: The importance of team members' need for cognition. Academy of Management Journal, 52: 581-598.

Keck, S. 1997. Top management team structure: Differ- ential effects by environmental context. Organization Science, 8: 143-156.

*Keller, R. T. 2001. Cross-functional project groups in research and new product development: Diversity, communications, job stress and outcomes. Academy of Management Journal, 44: 547-555.

${ }^{*}$ Kirkman, B. L., Tesluk, P. E., \& Rosen, B. 2004. The impact of demographic heterogeneity and team leader-team member demographic fit on team empowerment and effectiveness. Group and Organization Management, 29: 334-368.

Kochan, T., Bezrukova, K., Ely, R., Jackson, S., Joshi, A., Jehn, K. et al. 2003. The effects of diversity on business performance: Report of the diversity research network. Human Resource Management, 42: 3-21.

Larkey, L. K. 1996. Toward a theory of communicative interactions in culturally diverse workgroups. Academy of Management Review, 21: 463-491.

Lau, D. C., \& Murnighan, J. K. 1998. Demographic diversity and faultlines: The compositional dynamics of organizational groups. Academy of Management Review, 23: 325-340.

Lau, D. C., \& Murnighan, J. K. 2005. Interactions within groups and subgroups: The effects of demographic faultlines. Academy of Management Journal, 48: $645-659$.

Lawrence, P., \& Lorsch, J. 1967. Organization and its environment. Cambridge, MA: Harvard University Press.

*Leonard, J. S., Levine, D. I., \& Joshi, A. 2004. Do birds of a feather shop together? The effects on performance of employees' similarity with one another and with customers. Journal of Organizational Behavior, 25: 731-754.

LePine, J. A., Hanson, M. A., Borman, W. C., \& Motowidlo, S. J. 2000. Contextual performance and teamwork: Implications for staffing. In G. R. Ferris \& K. M. Rowland (Eds.), Research in personnel and human resources management, vol. 19: 53-90. Greenwich, CT: JAI Press.

Li, J., \& Hambrick, D. C. 2005. Factional groups: A new vantage on demographic faultlines, conflict, and disintegration in work teams. Academy of Management Journal, 48: 794-813.

Linnehan, F., \& Konrad, A. M. 1999. Diluting diversity: Implications for intergroup inequality in organizations. Journal of Management Inquiry, 8: 399-414.

Lipsey, M. W., \& Wilson, D. B. 2001. Practical metaanalysis. Thousand Oaks, CA: Sage.

*Lovelace, K., Shapiro, D. L., \& Weingart, L. R. 2001. Maximizing cross-functional new product teams' innovativeness and constraint adherence: A conflict communications perspective. Academy of Management Journal, 44: 779-793.

* Marsteller, J. A. 2003. The relationship between nonracial diversity in team composition and perfor- 
mance in creativity in a chronic illness care quality improvement intervention. Unpublished doctoral dissertation, University of California, Berkeley.

Martins, L. L., Miliken, F. J., Wiesenfeld, B. M., \& Salgado, S. R. 2003. Racioethnic diversity and group member's experience. Group and Organization Management, 28: 75-106.

Mayo, M., Pastor, J., \& Meindl, J. R. 1996. The effects of group heterogeneity on the self-perceived efficacy of group leaders. Leadership Quarterly, 7: 265-284.

McGrath, J. E. 1984. Groups: Interaction and performance. Englewood Cliffs, NJ: Prentice-Hall.

Milkovich, G. T. 1987. Compensation systems in high technology companies. In D. B. Balkin \& L. R. Gomez-Mejia (Eds.), New perspectives on compensation. Englewood Cliffs, NJ: Prentice-Hall.

Milliken, F. J., \& Martins, L. L. 1996. Searching for common threads: Understanding the multiple effects of diversity in organizational groups. Academy of Management Review, 21: 402-433.

Organisation for Economic Cooperation and Development. 2006. OECD science, technology and industry outlook. Organisation for Economic Cooperation and Development.

Orwin, R. G. 1983. A fail-safe $\mathrm{N}$ for effect size in meta-analysis. Journal of Educational Statistics, 8: 157-159.

Pelled, L. H. 1996. Relational demography and perceptions of group conflict and performance: A field investigation. International Journal of Conflict Management, 7: 230-246.

*Pelled, L. H., Eisenhardt, K. M., \& Xin, K. R. 1999. Exploring the black box: An analysis of work group diversity, conflict, and performance. Administrative Science Quarterly, 44: 1-28.

Perry, E. L. 1997. A cognitive approach to understanding discrimination: A closer look at applicant gender and race. In G. R. Ferris (Ed.), Research in personnel and human resource management, vol. 15: 175240. Greenwich, CT: JAI Press.

Pettigrew, T. F. 1998. Intergroup contact theory. In J. T. Spence, J. M. Darley, \& D. J. Foss (Eds.), Annual review of psychology, vol. 49: 65-85. Palo Alto, CA: Annual Reviews.

Porter, M. E. 1980. Competitive strategy. New York: Free Press.

*Portero-Brown, R. A. 1999. The missing link between team heterogeneity and effectiveness: Individual and contextual influences on social category salience. Unpublished doctoral dissertation, University of California, Berkeley.

*Puck, J., Rygl, D., \& Kittler, M. 2006. Cultural antecedents and performance consequences of open communication and knowledge transfer in multicultural process-innovation teams. Journal of Organiza- tional Transformation and Social Change, 3: 223-241.

Quinn, J. B., Anderson, P., \& Finkelstein, S. 1996. Leveraging intellect. Academy of Management Executive, 10(3): 7-27.

Ragins, B., \& Sundstorm, E. 1990. Gender and power organizations: A longitudinal perspective. Psychological Bulletin, 105: 51-88.

*Raver, J. L., \& Gelfand, M. J. 2005. Beyond the individual victim: Linking sexual harassment, team processes, and team performance. Academy of Management Journal, 48: 387-400.

*Reagans, R., \& Zuckerman, E. W. 2001. Networks, diversity, and productivity: The social capital of corporate R\&D teams. Organization Science, 12: 502-517.

Reagans, R., Zuckerman, E. W., \& McEvily, B. 2004. How to make the team: Social networks vs. demography as criteria for designing effective teams. Administrative Science Quarterly, 49: 101-133.

Reskin, B. F., McBrier, D. B., \& Kmec, J. 1999. The determinants and consequences of workplace sex and race composition. In J. Hagan \& K. Cook (Eds.), Annual review of sociology, vol. 25: 355-361. Palo Alto, CA: Annual Reviews.

Richard, O. C. 2000. Racial diversity, business strategy, and firm performance: A resource-based view. Academy of Management Journal, 43: 164-177.

Richard, O. C., Barnett, T., Dwyer, S., \& Chadwick, K. 2004. Cultural diversity in management, firm performance, and the moderating role of entrepreneurial orientation dimensions. Academy of Management Journal, 47: 255-266.

Richard, O. C., Murthi, B. P. S., \& Ismail, K. 2007. The impact of racial diversity on intermediate and longterm performance: The moderating role of environmental context. Strategic Management Journal, 28: 1213-1233.

Ridgeway, C. L. 1991. The social construction of status value: Gender and other nominal characteristics. Social Forces, 70: 367-386.

Ridgeway, C. L. 1997. Interaction and the conservation of gender inequality: Considering employment. American Sociological Review, 62: 218-235.

Rosen, B., \& Jerdee, T. H. 1977. Too old or not too old. Harvard Business Review, 55(6): 97-106.

Rosenthal, R. 1979. The "file drawer problem" and tolerance of null results. Psychological Bulletin, 86: $638-641$.

Rousseau, D. M., \& Fried, Y. 2001. Location, location, location: Contextualizing organizational research. Journal of Organizational Behavior, 22: 1-13.

Saavedra, R., Earley, P., \& Van Dyne, L. 1993. Complex interdependence in task-performing groups. Journal of Applied Psychology, 78: 61-72.

*Sacco, J. M., \& Schmitt, N. A. 2005. A dynamic multi- 
level model of demographic diversity and misfit effects. Journal of Applied Psychology, 90: 203-231.

*Schippers, M. C., Den Hartog, D. N., Koopman, P. L., \& Wienk, J. A. 2003. Diversity and team outcomes: The moderating effects of outcome interdependence and group longevity and the mediating effect of reflexivity. Journal of Organizational Behavior, 24: 779802.

Shea, G. P., \& Guzzo, R. A. 1987. Groups as human resources. In K. M. Rowland \& G. R. Ferris (Eds.), Research in personnel and human resource management, vol. 5: 323-356. Greenwich, CT: JAI Press.

Shore, L. M., \& Goldberg, C. B. 2005. Age discrimination in the workplace. In R. L. Dipboye \& A. Colella (Eds.), Discrimination at work: The psychological and organizational bases: 203-225. Mahwah, NJ: Erlbaum.

Sidanius, J. 1993. The psychology of group conflict and the dynamics of oppression: A social dominance perspective. In S. Iyengar \& W. J. McGuire (Eds.), Explorations in political psychology: 183-219. Durham, NC: Duke University Press.

Skaggs, S., \& DiTomaso, N. 2004. Understanding the effects of workforce diversity on employment outcomes: A multidisciplinary and comprehensive framework. In N. DiTomaso \& C. Post (Eds.), Research in the sociology of work: 279-306. New York: Elsevier.

*Somech, A. 2006. The effects of leadership style and team process on performance and innovation in functionally heterogeneous teams. Journal of Management, 32: 132-157.

Teachman, J. D. 1980. Analysis of population diversity. Social Methods and Research, 8: 341-362.

Thompson, J. D. 1967. Organizations in action. New York: McGraw-Hill.

*Tyran, K. L., \& Gibson, C. B. 2008. Is what you see, what you get? The relationship among surface- and deeplevel heterogeneity characteristics, group efficacy, and team reputation. Group and Organization Management, 33: 46-76.

U. S. Bureau of Labor Statistics. 2006. Labor force statistics from the Current Population Survey. Washington, DC: U. S. Department of Labor.

U. S. Bureau of Labor Statistics. 2007. Occupational outlook handbook, 2006-2007. Washington, DC: U.S. Department of Labor.

U. S. Census Bureau. 2002. North American Industry Classification System (NAICS)-Revisions for 2002. Washington, DC: U. S. Census Bureau.

*Van der Vegt, G. S., \& Bunderson, J. S. 2005. Learning and performance in multidisciplinary teams: The importance of collective team identification. Academy of Management Journal, 48: 532-547.

Van der Vegt, G. S., \& Janssen, O. 2003. Joint impact of interdependence and group diversity on innovation. Journal of Management, 29: 29-51.

Van der Vegt, G. S., Van de Vliert, E., \& Huang, X. 2005. Location-level links between diversity and innovative climate depend on national power distance. Academy of Management Journal, 48: 1171-1182.

Van de Ven, A. H., Delbecq, A. L., \& Koenig, R. 1976. Determinants of coordination modes within organizations. American Sociological Review, 41: 322338.

Van Knippenberg, D., De Dreu, C. K. W., \& Homan, A. C. 2004. Work group diversity and group performance: An integrative model and research agenda. Journal of Applied Psychology, 89: 1008-1022.

Van Knippenberg, D., \& Schippers, M. C. 2007. Workgroup diversity. In M. I. Posner \& M. K. Rothbart (Eds.), Annual review of psychology, vol. 58: 2.12.27. Palo Alto, CA: Annual Reviews.

Watson, W. E., Johnson, L., \& Merritt, D. 1998. Team orientation, self-orientation, and diversity in task groups: Their connection to team performance over time. Group and Organization Management, 23: 161-282.

Webber, S. S., \& Donahue, L. M. 2001. Impact of highly and less job-related diversity on work group cohesion and performance: A meta-analysis. Journal of Management, 27: 141-162.

Whitener, E. M. 1990. Confusion of confidence intervals and credibility intervals in meta-analysis. Journal of Applied Psychology, 75: 315-321.

Williams, K., \& O’Reilly, C. A. 1998. Demography and diversity in organizations: A review of 40 years of research. In B. M. Staw \& L. L. Cummings (Eds.), Research in organizational behavior, vol. 20: 77140. Greenwich, CT: JAI Press.

*Yeh, Y., \& Chou, H. 2005. Team composition and learning behaviors in cross-functional teams. Social Behavior and Personality, 33: 391-402.

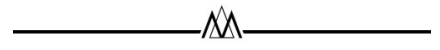

Aparna Joshi (aparnajo@illinois.edu) is an assistant professor of labor and employment relations at the University of Illinois, Urbana-Champaign. She received her Ph.D. from the School of Management and Labor Relations, Rutgers University. She conducts research in the area of work team diversity, global and distributed teams, team social capital, and generational issues in the workplace.

Hyuntak Roh (hroh2@illinois.edu) is a Ph.D. candidate in the School of Labor and Employment Relations at the University of Illinois at Urbana-Champaign. His research interests include workforce diversity, group process and performance, employee turnover, and multilevel contextual issues in HR/OB research. 
Copyright of Academy of Management Journal is the property of Academy of Management and its content may not be copied or emailed to multiple sites or posted to a listserv without the copyright holder's express written permission. However, users may print, download, or email articles for individual use. 